Article

\title{
Bioactive Bromotyrosine-Derived Alkaloids from the Polynesian Sponge Suberea ianthelliformis
}

\author{
Amr El-Demerdash ${ }^{1,2}$ (D), Céline Moriou ${ }^{1}$, Jordan Toullec ${ }^{3}$, Marc Besson ${ }^{4,5}$ (1), \\ Stéphanie Soulet ${ }^{6}$, Nelly Schmitt ${ }^{6}$, Sylvain Petek ${ }^{3}{ }^{(1)}$, David Lecchini ${ }^{4}$, Cécile Debitus ${ }^{3, *}$ and \\ Ali Al-Mourabit ${ }^{1, *}$ \\ 1 Institut de Chimie des Substances Naturelles, CNRS UPR 2301, University Paris-Sud, \\ University of Paris-Saclay, 1, Avenue de la Terrasse, 91198 Gif-Sur-Yvette, France; \\ eldemerdash555@gmail.com (A.E.-D.); Celine.Moriou@cnrs.fr (C.M.) \\ 2 Organic Chemistry Division, Chemistry Department, Faculty of Science, Mansoura University, \\ Mansoura 35516, Egypt \\ 3 LEMAR, IRD, UBO, CNRS, IFREMER, IUEM, 29280 Plouzané, France; \\ Jordan.Toullec@univ-brest.fr (J.T.); sylvain.petek@ird.fr (S.P.) \\ 4 CRIOBE, CNRS, EPHE, UPVD, PSL Research University, 98729 Moorea, French Polynesia; \\ bessonmarcluc@gmail.com (M.B.); david.lecchini@ephe.sorbonne.fr (D.L.) \\ 5 Observatoire Océanologique de Banyuls-sur-Mer, Université Pierre et Marie Curie Paris, \\ 66650 Banyuls-sur-Mer, France \\ 6 EIO, UPF, ILM, IFREMER, IRD, Faa'a, 98702 Tahiti, French Polynesia; \\ stephanie.soulet@upf.pf (S.S.); nelly.schmitt@upf.pf (N.S.) \\ * Correspondance: cecile.debitus@ird.fr (C.D.); Ali.ALMOURABIT@cnrs.fr (A.A.-M.); \\ Tel.: +336-0448-1378 (C.D.); +336-1585-9203 (A.A.-M.)
}

Received: 29 March 2018; Accepted: 24 April 2018; Published: 27 April 2018

\begin{abstract}
Herein, we describe the isolation and spectroscopic identification of eight new tetrabrominated tyrosine alkaloids 2-9 from the Polynesian sponge Suberea ianthelliformis, along with known major compound psammaplysene D (1), N,N-dimethyldibromotyramine, 5-hydroxy xanthenuric acid, and xanthenuric acid. Cytotoxicity and acetylcholinesterase inhibition activities were evaluated for some of the isolated metabolites. They exhibited moderate antiproliferative activity against KB cancer cell lines, but psammaplysene D (1) displayed substantial cytotoxicity as well as acetylcholinesterase inhibition with $\mathrm{IC}_{50}$ values of $0.7 \mu \mathrm{M}$ and $1.3 \mu \mathrm{M}$, respectively.
\end{abstract}

Keywords: brominated tyrosine alkaloids; Suberea ianthelliformis; cytotoxicity; acetylcholinesterase inhibition

\section{Introduction}

Sponges of the marine genus Suberea (order: Verongiida) are known to produce a large array of structurally diverse brominated tyrosine alkaloids, which are considered as chemotaxonomical markers [1-3]. Nevertheless, bromotyrosine-derived metabolites have been isolated from sponges belonging to distinct orders such as Agelasida [4] and others. In addition, an interesting recent study showed that culture of the marine sponge-derived bacterium Pseudovibrio denitrificans Ab134 isolated from the Arenosclera brasiliensis sponge (order Haplosclerida) can produce bromotyrosine-derived alkaloids as well [5]. Although misidentifications and contaminations due to misplaced specimens are possible, these reports compromise this family of compounds as a Verongiida marker and suggest staying cautious about secondary metabolites markers for sponge phylogeny [6]. The bromotyrosine derivatives' architectures vary from the simple monomeric molecules such as subereaphenol K [7], or the dimeric suberedamine A [8,9], to more complex derivatives like the well-known fistularin-3 [10]. 
Many compounds of this class of bromotyrosine alkaloids display a wide scope of bioactivities including cytotoxicity against murine leukemia L1201 cells and KB cells [8,9], DNA demethylating [11], antiproliferative [12], antimicrobial [13-16], and antiplasmodial activities [17]. In continuation of our search for bioactive marine natural products from South Pacific sponges [18], in both health and chemical ecology fields, we report here the isolation, structural determination, and cytotoxicity evaluation of eight new tetrabromotyrosine alkaloids (Figure 1), along with four known compounds from the sponge Suberea ianthelliformis. The known major compound psammaplysene D (1) was also evaluated for its acetylcholinesterase inhibition activity. Although acetylcholinesterase inhibition has been mostly explored as treatment for Alzheimer's pathology, our attention has been brought to the chemical ecology importance of such enzyme inhibitors in their environment or against predation [19]. Only one publication relates fish toxicity on Gambusia affinis (western mosquitofish) and butylcholinesterase from a Latrunculia magnifica toxin [20]. We describe our observations of the inhibitory effect of psammaplysene $D$ on acetylcholinesterase, using balneation experiments on two fish species, Poecilia reticulata (guppy) and Acanthurus triostegus (reef fish).<smiles>CN(C)CCCOc1c(Br)cc(/C=C/C(=O)N(C)CCCOc2c(Br)cc(CCN(C)C)cc2Br)cc1Br</smiles><smiles>CN(C)CCc1cc(Br)c(OCCCN(C)C(=O)/C=C/c2cc(Br)c(O)c(Br)c2)c(Br)c1</smiles><smiles>CN(C)CCc1cc(Br)c(OCCCN(C)C(=O)/C=C\c2cc(Br)c(O)c(Br)c2)c(Br)c1</smiles>

psammaplysene $\mathrm{F}(2)$ $\mathrm{Br}$ psammaplysene $\mathrm{G}(\mathbf{3})$<smiles>CNCCCOc1c(Br)cc(/C=C/C(=O)N(C)CCCOc2c(Br)cc(CCNC)cc2Br)cc1Br</smiles><smiles>CN(C)CCc1cc(Br)c(OCCCCN(C)C(Cc2cc(Br)c(O)c(Br)c2)C(=O)N(C)C)c(Br)c1</smiles>
psammaplysene I (5) $\mathrm{R}=\mathrm{H}$ anomoian $\mathrm{D}(7), \mathrm{R}=\mathrm{H}$<smiles>CN(C)CCCOc1cc(Br)c(CC(C(=O)N(C)CCCCOc2c(Br)cc(CCN(C)C)cc2Br)N(C)C)cc1Br</smiles><smiles>CN(C)CCc1cc(Br)c(O)c(Br)c1</smiles>

$\mathrm{N}, \mathrm{N}$-dimethyldibromotyramine (10) anomoian $\mathrm{F}(\mathbf{9}), \mathrm{R}=\mathrm{CH}_{3}$

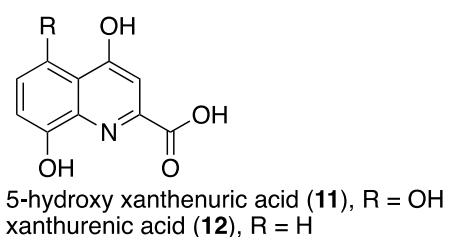

Figure 1. Structures of isolated compounds 1-12.

\section{Results and Discussion}

\subsection{Isolation and Structure Elucidation}

Each crude extract obtained by $\mathrm{CH}_{2} \mathrm{Cl}_{2}(10.5 \mathrm{~g})$ and $n-\mathrm{BuOH},(13 \mathrm{~g})$ of Suberea ianthelliformis was subjected to normal phase MPLC and eluted with gradients of $\mathrm{CH}_{2} \mathrm{Cl}_{2} / \mathrm{MeOH}$. The sub-fractions were purified by preparative, semi-preparative, and analytical reversed-phase HPLC and led to the isolation of eight new compounds 2-9, along with the known derivatives psammaplysene D (1), $\mathrm{N}, \mathrm{N}$-dimethyldibromotyramine (10), 5-hydroxy xanthurenic acid (11) and xanthurenic acid acid (12) (Figure 1). The known natural products psammaplysene D (1) [21], $N, N$-dimethyldibromotyramine (10) [22], 5-hydroxy xanthenuric acid (4,5,8-trihydroxyquinoline-2-carboxilic acid) (11) [23] and xanthurenic acid (12) [24] were identified by comparison of their ${ }^{1} \mathrm{H}$ NMR and MS data with those reported in the literature. It is worth to point out that psammaplysene $\mathrm{D}(\mathbf{1})$ was isolated by normal phase MPLC as the major compound $(6.7 \mathrm{~g})$ representing over $50 \%$ of the entire $n-\mathrm{BuOH}$ extract. 
The molecular formula $\mathrm{C}_{23} \mathrm{H}_{27}{ }^{79} \mathrm{Br}_{2}{ }^{81} \mathrm{Br}_{2} \mathrm{~N}_{2} \mathrm{O}_{3}$ of compound 2 was determined by HRESIMS $\left(\mathrm{m} / z 698.8675[\mathrm{M}+\mathrm{H}]^{+}\right)$indicating ten degrees of unsaturation. The isotopic pattern of the protonated molecule confirmed the presence of four bromines. Analysis of the NMR data recorded for 2 revealed striking similarities with the NMR data recorded for the co-isolated psammaplysene D (1), except for the absence of the signal corresponding to the propylamine group, as confirmed by the HRESIMS spectrum. In general, the ${ }^{1} \mathrm{H}$ NMR spectra of these families of compounds were complicated by the multiplicity of the signals due to the two rotational isomers trans/cis (6:4 ratio) along the amide bond [21]. The same behavior was already reported for tetrabromotyrosine derivatives psammaplysene A-D, isolated from the sponges Psammaplysilla and Psammoclemma [21-25]. The 1D and 2D NMR analysis revealed the existence of four aromatic protons comprising two singlets at $\delta_{\mathrm{H}} 7.78$ and 7.70, assigned to $\mathrm{H}-3 / 5$, and another broad singlet at $\delta_{\mathrm{H}} 7.57$ integrating for 2 protons, attributed to $\mathrm{H}-15 / 17$. An A-B system signal, corresponding to two olefinic protons at $\delta_{\mathrm{H}} 7.39-7.36 / 7.38-7.35(\mathrm{~J}=15.5 \mathrm{~Hz})$ and $\delta_{\mathrm{H}} 7.15-7.11 / 7.02-6.99(\mathrm{~J}=15.5 \mathrm{~Hz})$, were assigned to the $E$ olefin $-\mathrm{CH}-7=\mathrm{CH}-8-$, satisfying the tenth degree of unsaturation. The HMBC data analysis showed correlations between $\mathrm{H}-7$ and the two $\mathrm{sp}^{2}$ aromatic carbons $C-3 / 5\left(\delta_{C} 133.09 / 133.01\right)$ and the sp ${ }^{2}$ non-protonated carbon $C-4\left(\delta_{C} 130.98\right)$ confirming the connection of the trans-cinnamoyl motif to the 2,6-dibrominated phenolic ring (deduced with the chemical shifts of $C-2 / 6$ at $\delta_{C} 112.80$ and $C-1$ at $\left.\delta_{C} 154.10\right)$. The second olefinic proton $\mathrm{H}-8$ exhibited an HMBC correlation with the non-protonated carbon C-9 at $\left(\delta_{C} 168.96 / 168.80\right)$ linking this end to an amidic carbonyl function. HSQC and COSY spectra analysis allowed the assignment of the signals at $\delta_{\mathrm{H}} 4.11$ and $4.05(2 \mathrm{H}, 2 \mathrm{t}, J=6.4), 3.89$ and $3.74(2 \mathrm{H}, 2 \mathrm{t}, J=7.2 \mathrm{~Hz}), 2.22$ and 2.16 $(2 \mathrm{H}, 2 \mathrm{~m})$ to the three propylic carbon sequence $\mathrm{N}-\mathrm{CH}_{2}-10-\mathrm{CH}_{2}-11-\mathrm{CH}_{2}-12-\mathrm{O}$, while those at $\delta_{\mathrm{H}}$ $3.30(2 \mathrm{H}, \mathrm{m})$ and $3.00(2 \mathrm{H}, \mathrm{m})$ were attributed to the ethylic chain $\mathrm{CH}_{2}-19-\mathrm{CH}_{2}-20$. The protons $\mathrm{H}-20$ were correlated to $\mathrm{N}-\mathrm{Me}_{22}$ and $\mathrm{N}-\mathrm{Me}_{23}$ by $\mathrm{HMBC}$ analysis (Figure 2). The methylene group $\mathrm{CH}_{2}-10$ was connected to the amidic $N-\mathrm{Me}_{21}$ based on its chemical shift $\left(\delta_{C} 47.14 / 48.2\right)$ and the HMBC correlation to $C-9\left(\delta_{C} 168.96 / 168.80\right)$ and $C-21\left(\delta_{C} 34.74 / 36.55\right)$. The chemical shifts of $\mathrm{CH}_{2}-12$ at $\left(\delta_{\mathrm{H}} 4.11 / 4.05\right)$ and $\delta_{\mathrm{C}}(71.94 / 72.64)$ showed its link to the ether oxygen. Furthermore, the correlation of $\mathrm{H}-12$ to the non-protonated carbon $\mathrm{C}-13\left(\delta_{\mathrm{C}} 153.88 / 153.94\right)$ allowed the connection of this part of the molecule to the other 1,2,4,6-tetrasubstituted-phenyl ring. Furthermore, $\mathrm{CH}_{2}-19\left(\delta_{\mathrm{H}} 3.00\right)$ displayed HMBC correlations with the aromatic non-protonated carbon C-16 $\left(\delta_{C} 136.81 / 136.99\right)$ and $\mathrm{CH}-15 / 17$ (134.63/134.56), confirming the substitution of this aromatic ring by the $N, N$-dimethylaminoethyl chain. Compound 2 was named psammaplysene F.

Compound 3 displayed the same molecular formula than compound 2 obtained by HRESIMS $\left(m / z 698.8675[\mathrm{M}+\mathrm{H}]^{+}\right)$. A preliminary ${ }^{1} \mathrm{H}$ NMR inspection (Table 1$)$ showed similarity between compounds 1 and 2, which was easily observed by superimposition of their spectra. The A-B system of two downfield doublets of doublets at $\delta_{\mathrm{H}} 6.49-6.52 / 6.56-6.58(\mathrm{~J}=12.5 \mathrm{~Hz}$, cis $)$ and $\delta_{\mathrm{H}}$ 6.13-6.16/6.09-6.12 $(\mathrm{J}=12.5 \mathrm{~Hz})$ were assigned to $-\mathrm{CH}-7=\mathrm{CH}-8$ of the cinnamoyl moiety with a $\mathrm{Z}$ configuration. Furthermore, the COSY, HSQC, and HMBC analysis data (Figure 2) showed the same correlations as previously found for $\mathbf{2}$. Thus, the tetrabrominated tyrosine $\mathbf{3}$ was assigned to psammaplysene G.

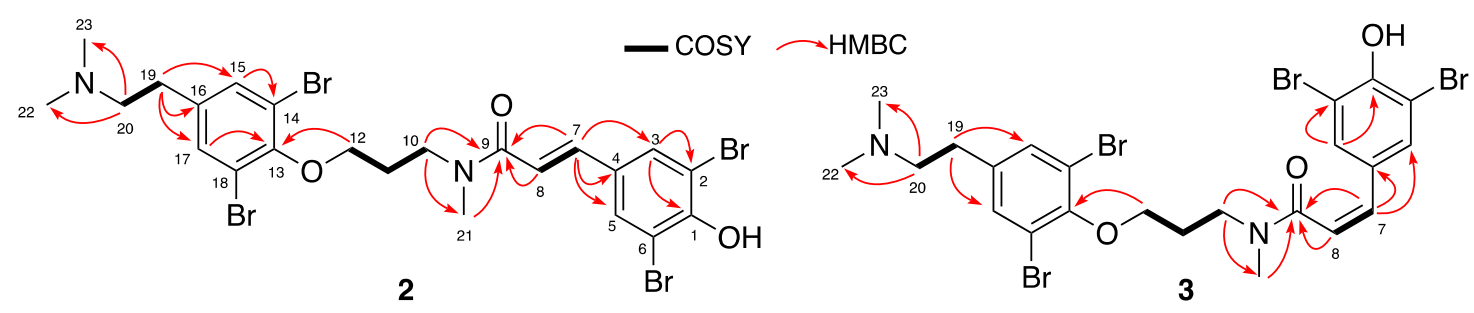

Figure 2. COSY and key HMBC correlations for psammaplysenes F (2) and G (3). 
Table 1. ${ }^{1} \mathrm{H}$ NMR (500 MHz) and ${ }^{13} \mathrm{C}$ NMR (125 MHz) data for Psammaplysenes F (2) and G (3) in $\mathrm{CD}_{3} \mathrm{OD}$.

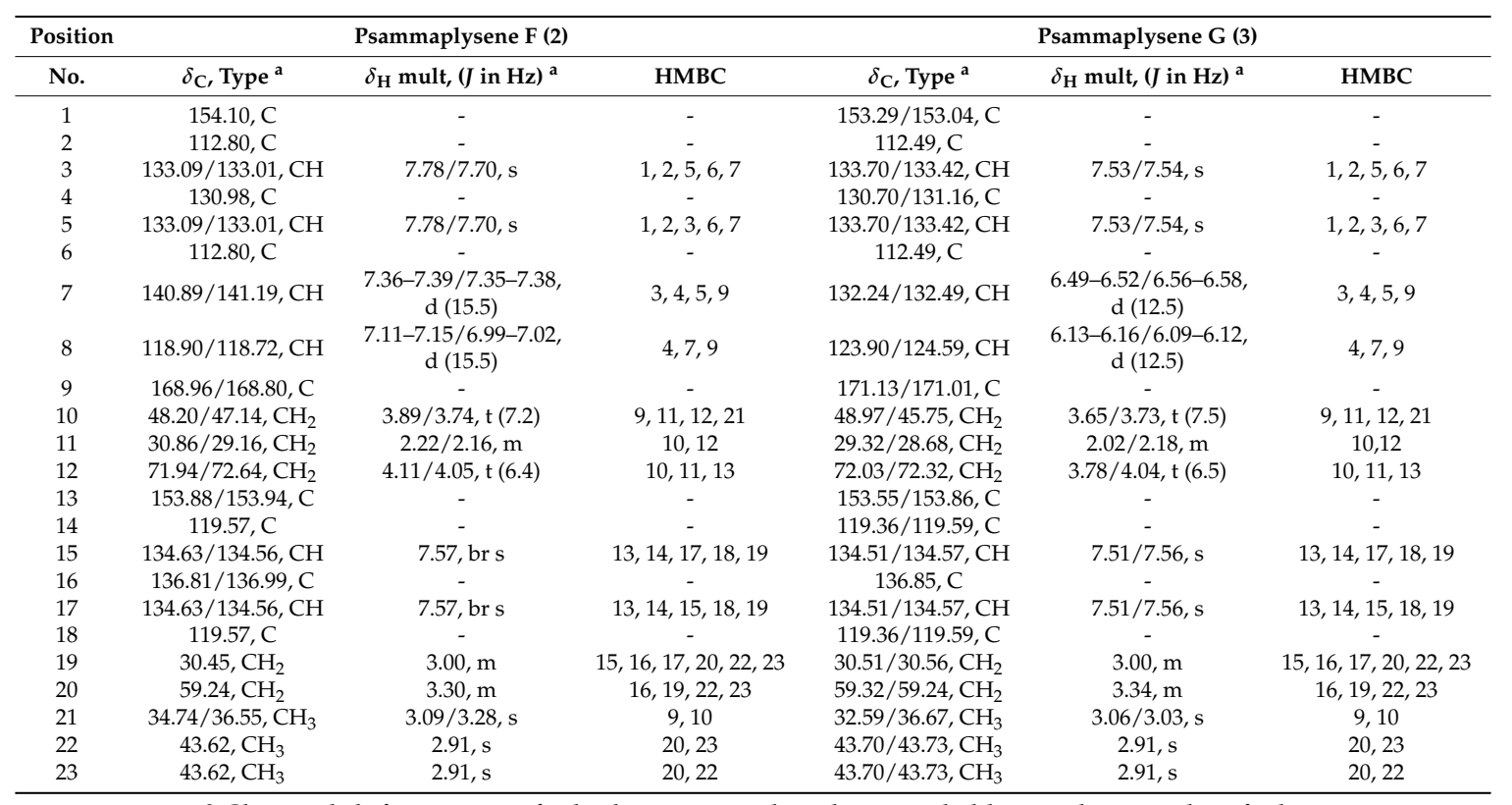

${ }^{a}$ Chemical shifts are given for both rotamers when distinguishable signals were identified.

Compounds 4 and 5 were obtained in a minute quantity $(0.7 \mathrm{mg})$ as a 1:1 mixture that could not be separated. Due to the minute quantity of the mixture, we decided to determine the structures of the latter two metabolites from the mixture. HRESIMS analysis revealed the molecular formulas $\mathrm{C}_{27} \mathrm{H}_{36}{ }^{79} \mathrm{Br}_{2}{ }^{81} \mathrm{Br}_{2} \mathrm{~N}_{3} \mathrm{O}_{3}\left(m / z 769.9521[\mathrm{M}+\mathrm{H}]^{+}\right)$and $\mathrm{C}_{26} \mathrm{H}_{34}{ }^{79} \mathrm{Br}_{2}{ }^{81} \mathrm{Br}_{2} \mathrm{~N}_{3} \mathrm{O}_{3}\left(m / z 755.9309[\mathrm{M}+\mathrm{H}]^{+}\right)$ for 4 and 5, with similar isotopic patterns indicating the presence of four bromines, but 14 and 28 a.m.u. (atomic mass unit) less than psammaplysene D (1), respectively. Direct comparison of the ${ }^{1} \mathrm{H} N M R$ spectra of this mixture (Table 2) and the co-isolated major compound psammaplysene D (1) showed good superimposition, including the rotameric forms. The main differences concerned the signals of $\mathrm{CH}_{2}-3^{\prime}, \mathrm{CH}_{2}-19$ and $\mathrm{CH}_{2}-20$ (Figure 3) indicating modifications of the number of the $\mathrm{N}$-methyl groups linked to them. The 2D NMR experiments (COSY, HSQC, and HMBC) of both compounds showed the same correlations as the co-isolated psammaplysene D (1) (Figure 2). ${ }^{1} \mathrm{H}$ NMR (Table 2) revealed four signals of $N$-methyl groups at $\delta_{\mathrm{H}} 3.10$ and $3.29\left(2 \mathrm{~s}, 6 \mathrm{H}\right.$, s-trans- $\left.\mathrm{CH}_{3}-21, \mathrm{~s}-\mathrm{cis}-\mathrm{CH}_{3}-21\right), \delta_{\mathrm{H}} 2.70$ $\left(\mathrm{s}, \mathrm{CH}_{3}-22,3 \mathrm{H}\right)$ and $\delta_{\mathrm{H}} 2.74-2.79\left(\mathrm{CH}_{3}-4^{\prime}\right.$ and $\left.\mathrm{CH}_{3}-5^{\prime}, 6 \mathrm{H}\right)$. The HMBC analysis showed correlation from $N-\mathrm{CH}_{3}-22\left(\delta_{\mathrm{H}} 2.70, \delta_{\mathrm{C}} 34.0\right)$ to $\mathrm{C}-20\left(\delta_{\mathrm{C}} 51.1\right)$ for compound 4 . The chemical shifts differences observed for $\mathrm{H}-19\left(\delta_{\mathrm{H}} 2.93\right), \mathrm{H}-20\left(\delta_{\mathrm{H}} 3.21\right)$ and $\mathrm{CH}_{3}-22\left(\delta_{\mathrm{H}} 2.70\right)$ suggested a modification on this part of the molecule. The chemical shifts of $\mathrm{C}-20\left(\delta_{\mathrm{C}} 51.1\right)$ and $\mathrm{CH}_{3}-22\left(\delta_{\mathrm{C}} 34.0\right)$ suggested the existence of only one methyl group on this side of the chain. At the other end of the molecule, correlations of $N-\mathrm{CH}_{3}-4^{\prime}$ and $5^{\prime}\left(\delta_{\mathrm{H}} 2.74-2.79, \delta_{\mathrm{C}} 44.7\right)$ to $\mathrm{C}-3^{\prime}\left(\delta_{\mathrm{C}} 57.2\right)$ along with the chemical shift of $\mathrm{C}-3^{\prime}$, showed the presence of two methyl groups on the nitrogen $\mathrm{N}-\mathrm{C}-3^{\prime}$. The chemical shift of C-20 and C-22 were the same for compound 5 , but the chemical shift of $C-2^{\prime}\left(\delta_{C} 27.9\right), C-3^{\prime}\left(\delta_{C} 48.7\right)$, and $\mathrm{CH}_{3}-4^{\prime}$ $\left(\delta_{C} 34.0\right)$, as well as the HMBC correlations between $\mathrm{C}-3^{\prime}$ and $\mathrm{CH}_{3}-4^{\prime}$, suggested the presence of a $\mathrm{NH}-\mathrm{Me}$ connected to the carbon $\mathrm{C}-3^{\prime}$. Therefore, our mixture was composed of two psammaplysene D derivatives lacking one and two $\mathrm{N}$-methyls and named psammaplysene $\mathrm{H}(4)$ and psammaplysene I (5), respectively. 


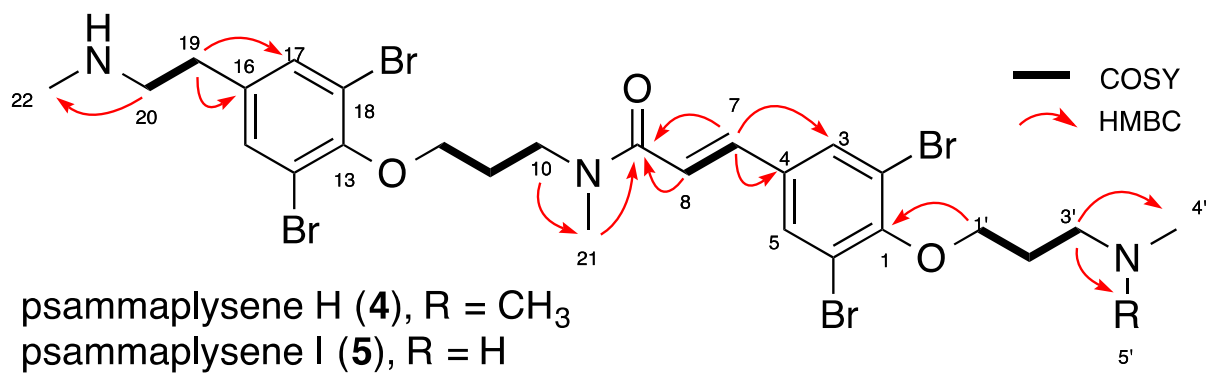

Figure 3. COSY and key HMBC correlations for psammaplysenes H (4) and I (5).

Table 2. ${ }^{1} \mathrm{H}$ NMR (500 MHz) and ${ }^{13} \mathrm{C}$ NMR (125 MHz) data for Psammaplysenes H (4) and I (5) in $\mathrm{CD}_{3} \mathrm{OD}$.

\begin{tabular}{|c|c|c|c|c|c|c|}
\hline \multirow{2}{*}{$\begin{array}{c}\text { Position } \\
\text { No }\end{array}$} & \multicolumn{3}{|c|}{ Psammaplysene H (4) } & \multicolumn{3}{|c|}{ Psammaplysene I (5) } \\
\hline & $\delta_{\mathrm{C}}$, Type $^{\mathrm{a}}$ & $\delta_{\mathrm{H}}$ mult, $(J \text { in } \mathrm{Hz})^{\mathrm{a}}$ & НМВС & $\delta_{\mathrm{C}}$, Type $^{\mathbf{a}}$ & $\delta_{\mathrm{H}}$ mult, $(J \text { in } \mathrm{Hz})^{\mathrm{a}}$ & НМВС \\
\hline 1 & $154.7, \mathrm{C}$ & - & - & $154.7, \mathrm{C}$ & - & - \\
\hline 2 & 119.6, C & - & - & 119.6, C & - & - \\
\hline 3 & $133.5 / 133.4, \mathrm{CH}$ & $7.92 / 7.85, \mathrm{~d}$ & $1,2,5,6,7$ & $133.5 / 133.4, \mathrm{CH}$ & $7.92 / 7.85, \mathrm{~d}$ & $1,2,5,6,7$ \\
\hline 4 & $136.2, \mathrm{C}$ & - & - & $136.2, \mathrm{C}$ & - & - \\
\hline 5 & $133.5 / 133.4, \mathrm{CH}$ & $7.92 / 7.85, \mathrm{~d}$ & $1,2,3,6,7$ & $133.5 / 133.4, \mathrm{CH}$ & $7.92 / 7.85, \mathrm{~d}$ & $1,2,3,6,7$ \\
\hline 6 & $119.6, \mathrm{C}$ & - & - & $119.6, \mathrm{C}$ & - & - \\
\hline 7 & $140.2 / 140.0, \mathrm{CH}$ & $7.40-7.44, \mathrm{~m}$ & $3,4,5,9$ & $140.2 / 140.0, \mathrm{CH}$ & $7.40-7.44, \mathrm{~m}$ & $3,4,5,9$ \\
\hline 8 & $121.6 / 121.7, \mathrm{CH}$ & $7.14-7.27, \mathrm{dd}(15.0)$ & $4,7,9$ & $121.6 / 121.7, \mathrm{CH}$ & $7.14-7.27, \mathrm{dd}(15.0)$ & $4,7,9$ \\
\hline 9 & $168.5, \mathrm{C}^{\mathrm{a}}$ & - & - & $168.5, C^{a}$ & - & - \\
\hline 10 & $48.4 / 47.3, \mathrm{CH}_{2}$ & $3.91 / 3.76, \mathrm{t}(7.0)$ & $9,11,12,21$ & $48.4 / 47.3, \mathrm{CH}_{2}$ & $3.91 / 3.76, \mathrm{t}(7.0)$ & $9,11,12,21$ \\
\hline 11 & $30.6 / 29.1, \mathrm{CH}_{2}$ & $2.23 / 2.17, \mathrm{~m}$ & 10,12 & $30.6 / 29.1, \mathrm{CH}_{2}$ & $2.23 / 2.17, \mathrm{~m}$ & 10,12 \\
\hline 12 & $72.6 / 71.9, \mathrm{CH}_{2}$ & $4.12 / 4.07, \mathrm{~m}$ & $10,11,13$ & $72.6 / 71.9, \mathrm{CH}_{2}$ & $4.12 / 4.07, \mathrm{~m}$ & $10,11,13$ \\
\hline 13 & $154.7, \mathrm{C}$ & - & - & $154.7, \mathrm{C}$ & - & - \\
\hline 14 & $119.6, \mathrm{C}$ & - & - & 119.6, C & - & - \\
\hline 15 & $134.5, \mathrm{CH}$ & $7.56 / 7.53, \mathrm{~m}$ & $13,14,17,18,19$ & $134.5, \mathrm{CH}$ & $7.56 / 7.53, \mathrm{~m}$ & $13,14,17,18,19$ \\
\hline 16 & $137.8, \mathrm{C}^{\mathrm{b}}$ & - & - & $137.8, \mathrm{C}^{\mathrm{b}}$ & - & - \\
\hline 17 & $134.5, \mathrm{CH}$ & $7.56 / 7.53, \mathrm{~m}$ & $13,14,15,18,19$ & $134.5, \mathrm{CH}$ & $7.56 / 7.53, \mathrm{~m}$ & $13,14,15,18,19$ \\
\hline 18 & 119.6, C & - & - & $119.6, \mathrm{C}$ & - & - \\
\hline 19 & $32.2, \mathrm{CH}_{2}$ & $2.93, \mathrm{t}(8.0)$ & $16,20,22$ & $32.2, \mathrm{CH}_{2}$ & $2.93, \mathrm{t}(8.0)$ & $16,20,22$ \\
\hline 20 & $51.1, \mathrm{CH}_{2}$ & $3.21, \mathrm{~m}$ & $16,19,22$ & $51.1, \mathrm{CH}_{2}$ & $3.21, \mathrm{~m}$ & $16,19,22$ \\
\hline 21 & $34.7 / 36.6, \mathrm{CH}_{3}$ & $3.10 / 3.29, \mathrm{~s}$ & 9,10 & $34.7 / 36.6, \mathrm{CH}_{3}$ & $3.10 / 3.29, \mathrm{~s}$ & 9,10 \\
\hline 22 & $34.0, \mathrm{CH}_{3}$ & $2.70, \mathrm{~s}$ & 20 & $34.0, \mathrm{CH}_{3}$ & $2.70, \mathrm{~s}$ & 20 \\
\hline $1^{\prime}$ & $57.2, \mathrm{CH}_{2}$ & $3.27, \mathrm{~m}$ & $1,2^{\prime}, 3^{\prime}$ & 48.7, $\mathrm{CH}_{2}$ & $3.35, \mathrm{~m}$ & $1,2^{\prime}, 3^{\prime}$ \\
\hline $2^{\prime}$ & $27.6, \mathrm{CH}_{2}$ & $2.23, \mathrm{~m}$ & $1^{\prime}, 3^{\prime}$ & $30.9 \mathrm{CH}_{2}$ & $2.23, \mathrm{~m}$ & $1^{\prime}, 3^{\prime}$ \\
\hline $3^{\prime}$ & $71.9, \mathrm{CH}_{2}$ & $4.18, \mathrm{~m}$ & $1^{\prime}, 2^{\prime}, 4^{\prime}, 5^{\prime}$ & $71.9, \mathrm{CH}_{2}$ & $4.18, \mathrm{~m}$ & $1^{\prime}, 2^{\prime}, 4^{\prime}$ \\
\hline $4^{\prime}$ & $44.3, \mathrm{CH}_{3}$ & $2.78 / 2.74, \mathrm{~s}$ & $3^{\prime}, 5^{\prime}$ & $34.0, \mathrm{CH}_{3}$ & $2.77 / 2.76, \mathrm{~s}$ & $3^{\prime}$ \\
\hline $5^{\prime}$ & $44.3, \mathrm{CH}_{3}$ & $2.79 / 2.74, \mathrm{~s}$ & $3^{\prime}, 4^{\prime}$ & - & - & - \\
\hline
\end{tabular}

${ }^{a}$ Chemical shifts are given for both rotamers when distinguishable signals were identified; ${ }^{b}$ Detected by HMBC correlations.

Compounds 6 and 7 exhibited the molecular formula were determined by HRESIMS as $\mathrm{C}_{25} \mathrm{H}_{33}{ }^{79} \mathrm{Br}_{2}{ }^{81} \mathrm{Br}_{2} \mathrm{~N}_{3} \mathrm{O}_{3}$ at $m / z 743.9386[\mathrm{M}+\mathrm{H}]^{+}$, and $\mathrm{C}_{24} \mathrm{H}_{31}{ }^{79} \mathrm{Br}_{2}{ }^{81} \mathrm{Br}_{2} \mathrm{~N}_{3} \mathrm{O}_{3}$ at $m / z 729.9190[\mathrm{M}+\mathrm{H}]^{+}$ respectively, indicating nine degrees of unsaturation with an isotopic pattern of four bromines. These NMR and mass data showed that compound 7 has one methyl group less than compound 6. Examination of the ${ }^{1} \mathrm{H}$ NMR and HSQC spectra (Table 3) displayed signals with similar chemical shifts to those reported for the tetrabromotyrosine compounds anomoians A and B, previously isolated from Anomoianthella popeae [26] (order: Verongiida) and from an unknown species of the genus Hexadella (order: Verongiida) collected in Indonesia [27]. 2D NMR analysis including COSY, HSQC, and HMBC (Table 3, Figure 4), allowed identification of the structures of 6 and 7 as the $O$-demethyl anomoian $B$ and O-demethyl anomoian A, respectively. Thus, the new compounds were named anomoian $\mathrm{C}$ (6) and anomoian $\mathrm{D}(7)$. The ${ }^{1} \mathrm{H}$ NMR signals of the aromatic protons $\mathrm{CH}-3 / 5$ and $\mathrm{CH}-15 / 17$ of these new compounds indicated a $6: 4$ rotameric proportionality. 


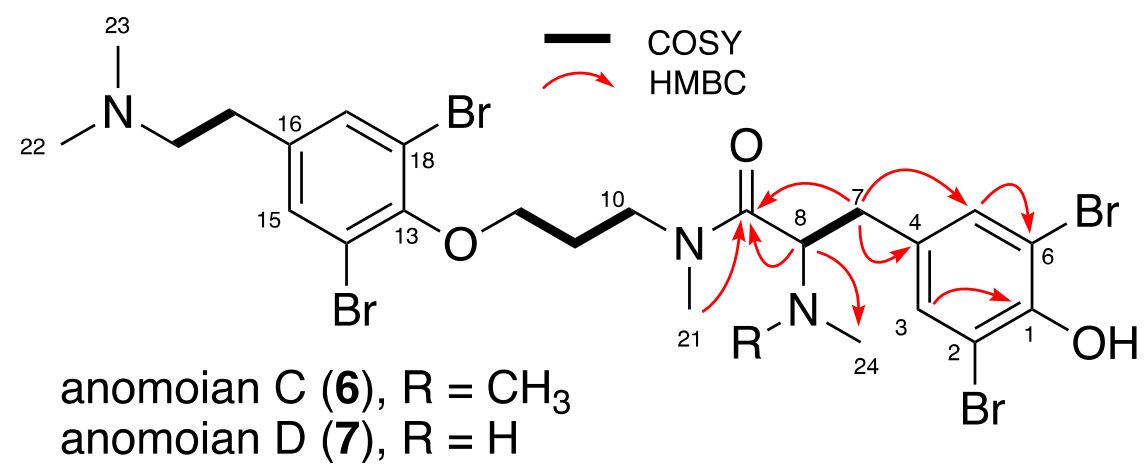

Figure 4. COSY and key HMBC correlations for anomoians C (6) and D (7).

Table 3. ${ }^{1} \mathrm{H}$ NMR $(500 \mathrm{MHz})$ and ${ }^{13} \mathrm{C}$ NMR (125 MHz) data for Anomoians C (6) and D (7) in $\mathrm{CD}_{3} \mathrm{OD}$.

\begin{tabular}{|c|c|c|c|c|c|c|}
\hline \multirow{2}{*}{$\begin{array}{c}\text { Position } \\
\text { No }\end{array}$} & \multicolumn{3}{|c|}{ Anomoian C (6) } & \multicolumn{3}{|c|}{ Anomoian D (7) } \\
\hline & $\delta_{\mathrm{C}}$, Type $^{\mathrm{a}}$ & $\delta_{\mathrm{H}}$ mult, $(J \text { in } \mathrm{Hz})^{\mathrm{a}}$ & НМВС & $\delta_{\mathrm{C}}$, Type $^{\mathrm{a}}$ & $\delta_{\mathrm{H}}$ mult, $(J \text { in } \mathrm{Hz})^{\mathrm{a}}$ & HMBC \\
\hline 1 & 151.65/151.47, C & - & - & $152.7, \mathrm{C}$ & - & - \\
\hline 2 & $112.36, \mathrm{C}$ & - & - & $112.69, \mathrm{C}$ & - & - \\
\hline 3 & $134.47 / 134.41, \mathrm{CH}$ & $7.34 / 7.32, \mathrm{~s}$ & $1,2,4,5,6,7$ & 134.40, CH & $7.37 / 7.35, \mathrm{~s}$ & $1,2,4,5,6,7$ \\
\hline 4 & $132.77 / 133.49, \mathrm{C}$ & - & - & $130.53 / 129.90, \mathrm{C}$ & - & - \\
\hline 5 & $134.47 / 134.41, \mathrm{CH}$ & $7.34 / 7.32, \mathrm{~s}$ & $1,2,3,4,6,7$ & $134.40, \mathrm{CH}$ & $7.37 / 7.35, \mathrm{~s}$ & $1,2,3,4,6,7$ \\
\hline 6 & $112.36, \mathrm{C}$ & - & - & $112.69, \mathrm{C}$ & - & - \\
\hline 7 & $33.14 / 32.14, \mathrm{CH}_{2}$ & $2.90 / 2.83-2.99, \mathrm{~m}$ & $3,4,5,8,9$ & $37.40 / 38.02, \mathrm{CH}_{2}$ & $2.83-3.04 / 2.92, \mathrm{~m}$ & $3,4,5,8,9$ \\
\hline 8 & $66.86, \mathrm{CH}$ & $3.82, \mathrm{~m}$ & $7,9,24,25$ & $60.79 / 61.29, \mathrm{CH}$ & $4.26 / 4.17, \mathrm{~m}$ & $7,9,24$ \\
\hline 9 & $172.36 / 172.63, \mathrm{C}$ & - & - & $171.40 / 172.00, \mathrm{C}$ & - & - \\
\hline 10 & $47.14 / 48.24, \mathrm{CH}_{2}$ & $3.40-3.72, \mathrm{~m}$ & $9,11,21$ & $47.67 / 47.78, \mathrm{CH}_{2}$ & $\begin{array}{c}3.48-3.80 / 3.26-3.51 \\
\mathrm{~m}\end{array}$ & $9,11,21$ \\
\hline 11 & $29.09 / 30.45, \mathrm{CH}_{2}$ & $\begin{array}{c}1.92-2.00 / 1.73-1.92 \\
\mathrm{~m}\end{array}$ & 10,12 & $29.15 / 30.50, \mathrm{CH}_{2}$ & $1.95-2.05 / 1.95, \mathrm{~m}$ & 10,12 \\
\hline 12 & $72.31 / 71.72, \mathrm{CH}_{2}$ & $3.85-3.93 / 3.88, \mathrm{~m}$ & 11,13 & $72.35 / 71.61, \mathrm{CH}_{2}$ & $3.97 / 3.99, \mathrm{~m}$ & 11,13 \\
\hline 13 & $153.61 / 153.30, \mathrm{C}$ & - & - & $153.72, \mathrm{C}$ & - & - \\
\hline 14 & $119.43, \mathrm{C}$ & - & - & $119.47, \mathrm{C}$ & - & - \\
\hline 15 & $134.47 / 134.50, \mathrm{CH}$ & $7.52 / 7.53, \mathrm{~s}$ & $13,14,16,17,18,19$ & $134.51 / 134.53, \mathrm{CH}$ & $7.54 / 7.55, \mathrm{~s}$ & $13,14,16,17,18,19$ \\
\hline 16 & 137.97/138.24, C & - & - & $137.72, \mathrm{C}$ & - & - \\
\hline 17 & $134.47 / 134.50, \mathrm{CH}$ & $7.52 / 7.53, \mathrm{~s}$ & $13,14,15,16,18,19$ & $134.51 / 134.53, \mathrm{CH}$ & $7.54 / 7.55, \mathrm{~s}$ & $13,14,15,16,18,19$ \\
\hline 18 & $119.43, \mathrm{C}$ & - & - & $119.47, \mathrm{C}$ & - & - \\
\hline 19 & $31.40 / 31.46, \mathrm{CH}_{2}$ & $2.92, \mathrm{~m}$ & $15,16,17,20$ & $31.22, \mathrm{CH}_{2}$ & $2.93, \mathrm{~m}$ & $15,16,17,20$ \\
\hline 20 & $60.12 / 60.14, \mathrm{CH}_{2}$ & $3.08, \mathrm{~m}$ & $16,19,22,23$ & $59.96, \mathrm{CH}_{2}$ & $3.21, \mathrm{~m}$ & $16,19,22,23$ \\
\hline 21 & $36.64 / 34.26, \mathrm{CH}_{3}$ & $2.92 / 2.93, \mathrm{~s}$ & 9,10 & $36.25 / 34.29, \mathrm{CH}_{3}$ & $2.50 / 2.47, \mathrm{~s}$ & 9,10 \\
\hline 22 & $44.30 / 44.34, \mathrm{CH}_{3}$ & $2.72 / 2.71, \mathrm{~s}$ & 20,23 & $44.18 / 44.21, \mathrm{CH}_{3}$ & $2.74 / 2.74, \mathrm{~s}$ & 20,23 \\
\hline 23 & $44.30 / 44.34, \mathrm{CH}_{3}$ & $2.72 / 2.71, \mathrm{~s}$ & 20,22 & $44.18 / 44.21, \mathrm{CH}_{3}$ & $2.74 / 2.74, \mathrm{~s}$ & 20,22 \\
\hline 24 & $42.31 / 41.19, \mathrm{CH}_{3}$ & $2.45 / 2.42, \mathrm{~s}$ & 8,25 & $33.26 / 33.68, \mathrm{CH}_{3}$ & $2.82 / 3.00, \mathrm{~s}$ & 8 \\
\hline 25 & $42.31 / 41.19, \mathrm{CH}_{3}$ & $2.45 / 2.42, \mathrm{~s}$ & 8,24 & - & - & - \\
\hline
\end{tabular}

${ }^{\mathrm{a}}$ Chemical shifts are given for both rotamers when distinguishable signals were identified.

Compound 8 had a protonated molecular ion at $m / z 815.0068[\mathrm{M}+\mathrm{H}]^{+}$corresponding to the molecular formula $\mathrm{C}_{29} \mathrm{H}_{43}{ }^{79} \mathrm{Br}_{2}{ }^{81} \mathrm{Br}_{2} \mathrm{~N}_{4} \mathrm{O}_{3}$, determined by HRESIMS. The mass spectrum indicated an isotopic matrix of a tetrabrominated compound. Quick examination of the ${ }^{1} \mathrm{H}$ NMR spectrum (Table 4) showed signals with identical chemical shifts to those reported for anomoian C (6) and D (7). Furthermore, it revealed the presence of an additional dimethylaminopropylic chain, as observed for psammaplysene D (1). This was confirmed by the 2D NMR spectra analysis, including COSY, HSQC, and HMBC, enabling us to set the correlations shown in Figure 5. The new compound $\mathbf{8}$ was named anomoian E.

The HRESIMS data of 9 revealed the molecular formula $\mathrm{C}_{30} \mathrm{H}_{45}{ }^{79} \mathrm{Br}_{2}{ }^{81} \mathrm{Br}_{2} \mathrm{~N}_{4} \mathrm{O}_{3}(m / z 829.0259$ $[\mathrm{M}+\mathrm{H}]^{+}$). Its ${ }^{1} \mathrm{H}$ NMR spectrum was very similar to anomoian $\mathrm{E}$ (8) spectrum, except for the two additional methyl groups at $\delta_{\mathrm{H}} 2.51 / 2.54$ integrating for six protons for 9. HSQC, COSY, and $\mathrm{HMBC}$ spectra analysis led to the same correlations as in compound 8 and enabled the assignment of the $N$-8-methyl groups through an additional correlation from the $N-\mathrm{CH}_{3}-24 / 25\left(\delta_{\mathrm{H}} 2.51 / 2.54,6 \mathrm{H}\right)$ to the methine group $\mathrm{CH}-8\left(\delta_{\mathrm{H}} 3.97 / 3.89, \mathrm{~m} ; \delta_{\mathrm{C}} 66.79 / 66.58\right)$. Therefore, structure 9 was determined as anomoian F, existing as 6:4 rotamers (Table 4, Figure 5). 


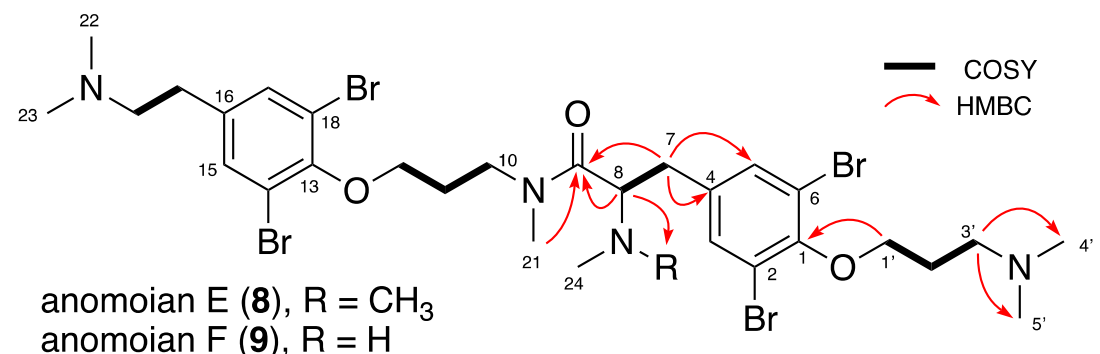

Figure 5. COSY and key HMBC correlations for anomoians E (8) and F (9).

Table 4. ${ }^{1} \mathrm{H}$ NMR (500 MHz) and ${ }^{13} \mathrm{C}$ NMR (125 MHz) data for Anomoians E (8) and F (9) in $\mathrm{CD}_{3} \mathrm{OD}$.

\begin{tabular}{|c|c|c|c|c|c|c|}
\hline Position & & Anomoian E (8) & & & Anomoian F (9) & \\
\hline No & $\delta_{\mathrm{C}}$, Type $^{\mathrm{a}}$ & $\delta_{\mathrm{H}}$ mult, $(J \text { in } \mathrm{Hz})^{\mathrm{a}}$ & НМВС & $\delta_{\mathrm{C}}$, Type $^{\mathrm{a}}$ & $\delta_{\mathrm{H}}$ mult, $(J \text { in } \mathrm{Hz})^{\mathrm{a}}$ & НМВС \\
\hline 1 & 153.29/153.15, C & - & - & 152.76/152.57, C & - & - \\
\hline 2 & 119.08.119.14, C & - & - & $118.92, \mathrm{C}$ & - & - \\
\hline 3 & $135.35 / 135.19, \mathrm{CH}$ & $7.51 / 7.48, \mathrm{~s}$ & $1,2,5,6,7$ & $135.32 / 135.22, \mathrm{CH}$ & $7.51 / 7.48, \mathrm{~s}$ & $1,2,5,6,7$ \\
\hline 4 & 137.14/138.15, C & - & - & 138.66/137.72, C & - & - \\
\hline 5 & 135.35/135.19, CH & $7.51 / 7.48, \mathrm{~s}$ & $1,2,3,6,7$ & $135.32 / 135.22, \mathrm{CH}$ & $7.51 / 7.48, \mathrm{~s}$ & $1,2,3,6,7$ \\
\hline 6 & 119.08.119.14, C & - & - & $118.92, \mathrm{C}$ & - & - \\
\hline 7 & $38.03 / 38.65, \mathrm{CH}_{2}$ & $2.84-3.03 / 2.93, \mathrm{~m}$ & $3,4,5,8,9$ & $33.05 / 31.91, \mathrm{CH}_{2}$ & $3.00 / 2.92-3.07, \mathrm{~m}$ & $3,4,5,8,9$ \\
\hline 8 & $60.72 / 61.23, \mathrm{CH}$ & $4.15 / 4.06, \mathrm{~m}$ & $4,7,9,24$ & 66.58/66.79, CH & $3.97 / 3.89, \mathrm{~m}$ & $4,7,9,24,25$ \\
\hline 9 & 172.73/173.46, C & - & - & 172.10/171.65, C & - & - \\
\hline 10 & $47.57 / 47.82, \mathrm{CH}_{2}$ & $\begin{array}{c}3.51-3.76 / 3.26-3.60 \\
\mathrm{~m}\end{array}$ & $9,11,12,21$ & $48.26 / 47.36, \mathrm{CH}_{2}$ & $\begin{array}{c}3.41-3.74 / 3.51-3.64 \\
\mathrm{~m}\end{array}$ & $9,11,12,21$ \\
\hline 11 & $29.16 / 30.64, \mathrm{CH}_{2}$ & $1.95-2.03 / 1.95, \mathrm{~m}$ & 10,12 & $30.71 / 29.08, \mathrm{CH}_{2}$ & $\begin{array}{c}1.69-1.98 / 1.90-1.98 \\
\mathrm{~m}\end{array}$ & 10,12 \\
\hline 12 & 72.36/71.71, $\mathrm{CH}_{2}$ & $3.99, \mathrm{~m}$ & $10,11,13$ & $71.82 / 72.40, \mathrm{CH}_{2}$ & $3.94 / 3.95, \mathrm{~m}$ & $10,11,13$ \\
\hline 13 & $153.54, \mathrm{C}$ & - & - & 153.77/153.51, C & - & - \\
\hline 14 & $119.42, \mathrm{C}$ & - & - & $119.52, \mathrm{C}$ & - & - \\
\hline 15 & $134.54 / 134.52, \mathrm{CH}$ & $7.55 / 7.56, \mathrm{~s}$ & $13,14,17,18,19$ & $134.57 / 134.60, \mathrm{CH}$ & $7.57 / 7.58, \mathrm{~s}$ & $13,14,17,18,19$ \\
\hline 16 & 137.74/138.52, C & - & - & 137.28, C & - & - \\
\hline 17 & $134.54 / 134.52, \mathrm{CH}$ & $7.55 / 7.56, \mathrm{~s}$ & $13,14,15,18,19$ & $134.57 / 134.60, \mathrm{CH}$ & $7.57 / 7.58, \mathrm{~s}$ & $13,14,15,18,19$ \\
\hline 18 & $119.42, \mathrm{C}$ & - & - & $119.52, \mathrm{C}$ & - & - \\
\hline 19 & $31.31 / 31.41, \mathrm{CH}_{2}$ & $2.93, \mathrm{~m}$ & $15,16,17,20$ & $30.67 / 30.59, \mathrm{CH}_{2}$ & $2.99, \mathrm{~m}$ & $15,16,17,20$ \\
\hline 20 & $60.01 / 60.08, \mathrm{CH}_{2}$ & $3.09, \mathrm{~m}$ & $16,19,22,23$ & $59.43, \mathrm{CH}_{2}$ & $3.26, \mathrm{~m}$ & $16,19,22,23$ \\
\hline 21 & $36.24 / 34.33, \mathrm{CH}_{3}$ & $2.88 / 2.99, \mathrm{~s}$ & 9,10 & $34.31 / 36.64, \mathrm{CH}_{3}$ & $2.92 / 2.94, \mathrm{~s}$ & 9,10 \\
\hline 22 & $44.19 / 44.24, \mathrm{CH}_{3}$ & $2.73 / 2.71, \mathrm{~s}$ & 20,23 & $43.75, \mathrm{CH}_{3}$ & $2.85 / 2.85, \mathrm{~s}$ & 20,23 \\
\hline 23 & $44.19 / 44.24, \mathrm{CH}_{3}$ & $2.73 / 2.71, \mathrm{~s}$ & 20,22 & $43.75, \mathrm{CH}_{3}$ & $2.85 / 2.85, \mathrm{~s}$ & 20,22 \\
\hline 24 & $33.71 / 34.11, \mathrm{CH}_{3}$ & $2.42 / 2.39, \mathrm{~s}$ & 4,8 & $42.23 / 42.07, \mathrm{CH}_{3}$ & $2.51 / 2.45, \mathrm{~s}$ & $4,8,25$ \\
\hline 25 & - & - & - & $42.23 / 42.07, \mathrm{CH}_{3}$ & $2.51 / 2.45, \mathrm{~s}$ & $4,8,24$ \\
\hline $1^{\prime}$ & $71.66 / 71.62, \mathrm{CH}_{2}$ & $4.09, \mathrm{~m}$ & $1,2^{\prime}, 3^{\prime}$ & $71.44, \mathrm{CH}_{2}$ & $4.01, \mathrm{t}(5.5)$ & $1,2^{\prime}, 3^{\prime}$ \\
\hline $2^{\prime}$ & $26.95, \mathrm{CH}_{2}$ & $2.25, \mathrm{~m}$ & $1^{\prime}, 3^{\prime}$ & $26.62, \mathrm{CH}_{2}$ & $2.27, \mathrm{~m}$ & $1^{\prime}, 3^{\prime}$ \\
\hline $3^{\prime}$ & $57.15, \mathrm{CH}_{2}$ & $3.36, \mathrm{~m}$ & $1^{\prime}, 2^{\prime}, 4^{\prime}, 5^{\prime}$ & $57.07, \mathrm{CH}_{2}$ & $3.45, \mathrm{~m}$ & $1^{\prime}, 2^{\prime}, 4^{\prime}, 5^{\prime}$ \\
\hline $4^{\prime}$ & $44.05, \mathrm{CH}_{3}$ & $2.85, \mathrm{~s}$ & $3^{\prime}, 5^{\prime}$ & $43.79, \mathrm{CH}_{3}$ & 2.92/2.91, s & $3^{\prime}, 5^{\prime}$ \\
\hline $5^{\prime}$ & $44.05, \mathrm{CH}_{3}$ & $2.85, \mathrm{~s}$ & $3^{\prime}, 4^{\prime}$ & $43.79, \mathrm{CH}_{3}$ & $2.92 / 2.91, \mathrm{~s}$ & $3^{\prime}, 4^{\prime}$ \\
\hline
\end{tabular}

${ }^{a}$ Chemical shifts are given for both rotamers when distinguishable signals were identified.

The absolute configuration of the stereocenter C-8 for anomoian C-F (6-9) can be proposed by comparison of the values and signs of their optical rotations in $\mathrm{MeOH}\left([\alpha]_{\mathrm{D}}^{25}+9^{\circ},+11^{\circ},+7^{\circ}\right.$ and $+6^{\circ}$, respectively), with the closely related congeners, anomoian $A\left([\alpha]_{D}+5.1^{\circ}\right)[26]$, anomoian $B\left([\alpha]_{D}\right.$ $\left.+10.5^{\circ}\right)[27]$, iso-Anomoian A $\left([\alpha]_{\mathrm{D}}^{20}+4.5^{\circ}\right)[28]$, suberedamines $\mathrm{A}\left([\alpha]_{\mathrm{D}}^{25}+21^{\circ}\right)$ and $\mathrm{B}\left([\alpha]_{\mathrm{D}}^{25}+16^{\circ}\right)[9]$, indicating that all are bearing L-tyrosine residue. The synthetic iso-Anomoian $A\left([\alpha]_{D}^{20}+4.5^{\circ}\right)$ and suberedamines $\mathrm{A}\left([\alpha]_{\mathrm{D}}^{20}+19.5^{\circ}\right)$ allowed the determination of their absolute configurations [28].

\subsection{Biological Activities}

The isolated compounds 1-3 and 6-11 were tested for their cytotoxic activity against human epidermoid carcinoma cells (KB) cancer cell lines (Table 5) and acetylcholinesterase. The results showed of the compounds exhibited moderate cytotoxicity. The major compound psammaplysene $\mathrm{D}$ (1) showed the most interesting cytotoxicity with an $\mathrm{IC}_{50}=0.7 \mu \mathrm{M}$. Anomoian E (8) and F (9), containing the $\mathrm{N}, \mathrm{N}$-dimethylaminopropyl side as psammaplysene $\mathrm{D}$, but lacking the double bond $-\mathrm{CH}-7=\mathrm{CH}-8$, displayed a lower activity. Moreover, psammaplysene F (2), which bear a trans-cinnamoyl part, was found to exhibit a lower activity than psammaplysene D (1). Therefore, from a structural 
point of view, both motifs ( $N, N$-dimethylaminopropyl and trans-cinnamoyl) seem to be together correlated to the activity of psammaplysene $\mathrm{D}(\mathbf{1})$.

Table 5. Cytotoxic activities in vitro (KB Cell Line) for compounds 1-3, 6-11.

\begin{tabular}{ccc}
\hline Compounds & $\mathbf{1 0} \boldsymbol{\mu} \mathbf{M}^{\mathbf{a}}$ & $\mathbf{1} \boldsymbol{\mu} \mathbf{M}^{\mathbf{a}}$ \\
\hline Psammaplysene D (1) & $100 \pm 0.2$ & $95 \pm 0.5$ \\
Psammaplysene F (2) & $73 \pm 2$ & $20 \pm 0.2$ \\
Psammaplysene G (3) & $75 \pm 0.4$ & $17 \pm 1$ \\
Anomoian C (6) & $28 \pm 5$ & $15 \pm 3$ \\
Anomoian D (7) & $29 \pm 2$ & $17 \pm 2$ \\
Anomoian E (8) & $82 \pm 1$ & $6 \pm 2$ \\
Anomoian F (9) & $100 \pm 0.5$ & $20 \pm 0.6$ \\
N,N-dimethyldibromotyramine (10) & $100 \pm 1$ & $89 \pm 1$ \\
5-hydroxy xanthenuric acid (11) & $25 \pm 1$ & $6 \pm 0.5$
\end{tabular}

a Cell proliferation was measured with Celltiter 96 Aqueous One solution reagent (Promega), and results are expressed as the percentage of inhibition of cellular proliferation of KB cells treated for $72 \mathrm{~h}$ with compounds compared to cells treated with DMSO only (mean \pm SE of triplicate).

The screening of our French Polynesian sponges extract library was performed on acetylcholinesterase inhibitor (AChE) in the aim to investigate a possible chemical defense of sessile organisms on the reef against fishes, their main predators. The chemical study of the bioactive extract of Suberea ianthelliformis using AChE led to the identification of psammaplysene $\mathrm{D}(\mathbf{1})$ as its unique in vitro $\mathrm{AChE}$ inhibitor with an $\mathrm{IC}_{50}=1.3 \mu \mathrm{M}$. None of the other closely related compounds displayed any activity on this target enhancing here again the importance of the phenoxy-1-N,N-dimethyl propane chain and the trans-cinnamoyl motifs (Figure 1). Further kinetics investigation of the mode of AChE inhibition of psammaplysene D (convergence of the lines on the Lineweaver Burk plot, decreasing $V_{\max }$ values (from 0.0036 to $0.0007 \mu \mathrm{mol} \cdot \mathrm{min}^{-1}$ ) and increasing $K_{\mathrm{M}}$ values (from 0.14 to $0.23 \mu \mathrm{M}$ )) suggested a mixed competitive/non-competitive inhibition suggesting that psammaplysene D (1) not only binds to the free enzyme, but also to the enzyme-substrate complex. In order to try to evaluate the effect of psammaplysene D in the environment, it was further tested on fresh water fish (guppy, Poecilia reticulata) and reef fish (Acanthurus triostegus) feeding experiment using bathing with or without the bioactive compound. Guppies are fed with commercial flakes, but the wild reef fish feed on natural coral heads, and their appetite evaluated by counting the bites on the corals. Two experiments were run on guppies using Suberea ianthelliformis crude extract and purified psammaplysene D (1): an acute toxicity bioassay (100 $\mathrm{\mu g} / \mathrm{mL}$ of crude extract or purified psammaplysene $\mathrm{D}(\mathbf{1}), 1 \mathrm{~h}$ ) and a chronic toxicity $(5 \mu \mathrm{g} / \mathrm{mL}$ of crude extract or $1 \mu \mathrm{g} / \mathrm{mL}$ of purified psammalysene $\mathrm{D}(\mathbf{1}), 72 \mathrm{~h}$ ).

During the acute exposure, fish were totally confused and had uncontrolled mobility, displaying sudden jumps and balance control loss, as soon as $20 \mathrm{~min}$ after the addition of psammaplysene D in the tank. This result can be compared to the observation reported by Nèeman et al. with Latrunculia species toxins [20]. Exposure of guppies during $24 \mathrm{~h}$ of at a sub-lethal dose $(5 \mu \mathrm{g} / \mathrm{mL}$ of crude extract or $1 \mu \mathrm{g} / \mathrm{mL}$ of purified psammalysene $\mathrm{D}(\mathbf{1})$ of the compound caused passivity of the fish towards the food flakes offered daily, whereas those of the controls ate normally. These observations indicate a clear link between the loss of appetite and psammaplysene D (1) toxicity. Similar activity was observed on reef fish recruits (fish larvae undergoing metamorphosis) of Acanthurus triostegus: the presence psammaplysene D (1) $(1 \mu \mathrm{g} / \mathrm{mL})$ in tanks significantly and readily decreased the number of bites of recruits, suggesting a rapid saturation of the environment perception sensors of the fish larvae during the $72 \mathrm{~h}$ of experiment (Figure 6). 

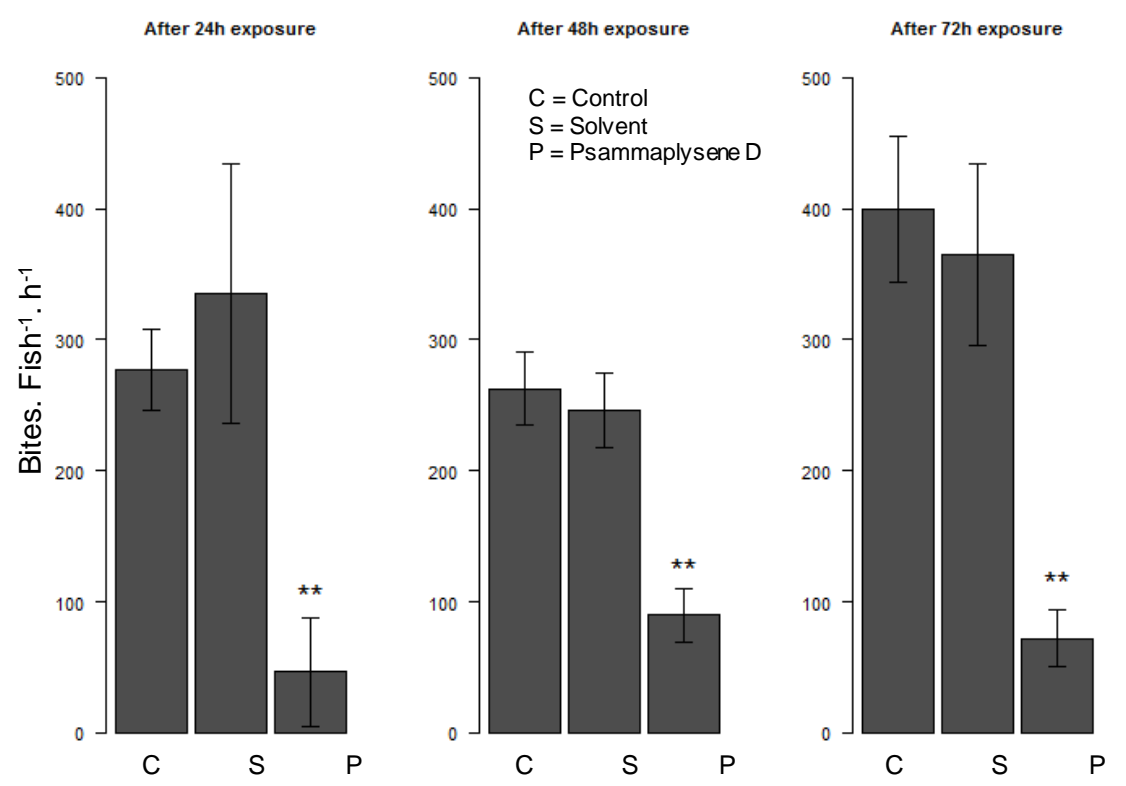

Figure 6. Number of bites on coral pieces per A. triostegus recruit and per hour. Error bars represent standard deviation of the mean $(N=6) .{ }^{* *} p<0.01$.

Psammaplysene D (1) displayed clearly behavioral effects on both guppies and reef fish larvae: they showed a loss of appetite from the first day of experiment. Reef fish juveniles' behavior did not seem to be impacted by psammaplysene $\mathrm{D}$. It is interesting to note that only $A$. triostegus larvae were impacted by the pure psammaplysene $\mathrm{D}$, suggesting a change of sensibility towards the compound during the metamorphosis. The toxicity test at a high dose $(100 \mu \mathrm{g} / \mathrm{mL}$ of crude extract or purified psammaplysene D) on the guppies led to their death after one hour bathing with either the crude extract or the purified psammaplysene D fraction (acute toxicity experiment). Brains and gills of these guppies were extracted and the AChE activity measured on the extracts (Figure 7a,b) [29]. The results were clearer with the purified psammaplysene $\mathrm{D}$, showing a mild but significant decrease of the activity of the enzyme in the gills, suggesting an action on the olfactory organs (peripheral nervous system) that could not be further investigated there. A great number of AChE inhibitors targeting Alzheimer's disease have been isolated from natural sources [30]. Among them, 6 compounds with activities ranging from $\mathrm{IC}_{50} 1$ to $100 \mu \mathrm{M}$ were isolated from Verongiida sponges (Table 6). It would be interesting also to further investigate those compounds as chemical anti-predatory defenses through fish antifeedant activity, since the fish model is easier to set up than related bioassays involving sponge predators, such as nudibranchs or crustaceans.

Brain

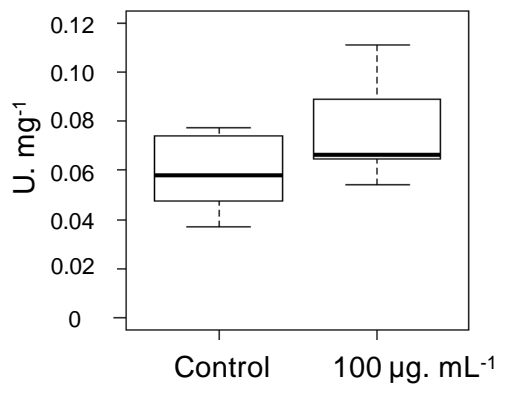

Gill

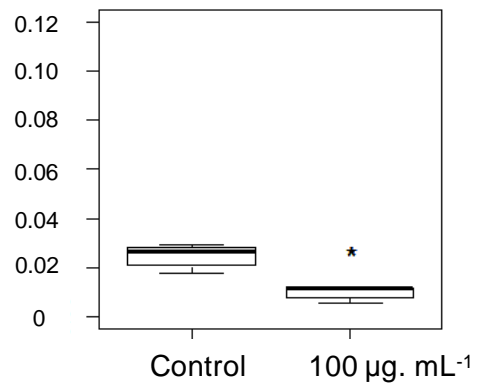

(a)

Figure 7. Cont. 

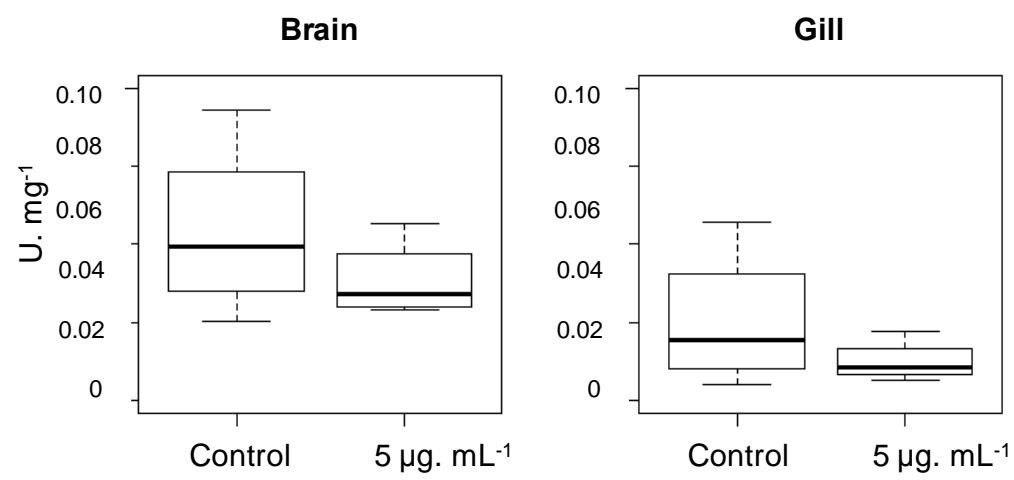

(b)

Figure 7. (a) AChE activity, $\mathrm{U} \cdot \mathrm{mg}^{-1}$, after $1 \mathrm{~h}$ exposure to $100 \mu \mathrm{g} / \mathrm{mL}$ of Psammalysene D (1). Boxplot distribution was made with 5 fish $(N=5)$. ${ }^{*} p<0.05$; (b) AChE activity, $\mathrm{U} \cdot \mathrm{mg}^{-1}$, after 72 h exposure to $5 \mu \mathrm{g} / \mathrm{mL}$ of crude extract. Boxplot distribution was made with 5 fish $(N=5)$.

Table 6. AChE inhibition of bromotyrosine compounds isolated from Verongiida sponges.

\begin{tabular}{|c|c|c|c|}
\hline Sponge/Compounds & AChE Origin Activities & & Reference \\
\hline $\begin{array}{l}\text { Pseudoceratina purpurea } \\
\text { Purealidine } \mathrm{Q} \\
\text { Isoanomoian } \mathrm{A} \\
\text { Aplysanzine } \mathrm{A}\end{array}$ & $\begin{array}{l}\text { Eel } \\
\mathrm{IC}_{50}=1.2 \mu \mathrm{M}\left(\mathrm{NCI}{ }^{\mathrm{a}}\right) \\
\mathrm{IC}_{50}=70 \mu \mathrm{M}(\mathrm{NCI}) \\
\mathrm{IC}_{50}=104 \mu \mathrm{M}(\mathrm{NCI})\end{array}$ & & Olatunji et al. 2014 [31] \\
\hline $\begin{array}{l}\text { Acanthodendrilla } \mathrm{sp} . \\
\text { Homoaerothionin } \\
\text { Fistularin } 1\end{array}$ & $\begin{array}{l}\text { Human recombinant AchE } \\
\mathrm{IC}_{50}=4.5 \mu \mathrm{M}\left(\mathrm{CI}^{\mathrm{b}}\right) \\
\mathrm{IC}_{50}=47.5 \mu \mathrm{M}\left(\mathrm{ND}^{\mathrm{c}}\right)\end{array}$ & & Sirimangkalakitti et al. 2015 [32] \\
\hline $\begin{array}{l}\text { Unidentified Verongida } \\
\text { Aplysamine- } 4\end{array}$ & $\begin{array}{l}\text { Eel } \\
\mathrm{K}_{\mathrm{I}}=16 \mu \mathrm{M}(\mathrm{NCI})\end{array}$ & $\begin{array}{l}\text { Insect recombinant } \\
\mathrm{K}_{\mathrm{I}}=2 \mu \mathrm{M}(\mathrm{NCI})\end{array}$ & Sepcic et al. 2001 [33] \\
\hline
\end{tabular}

${ }^{a}$ NCI: non competitive inhibition; ${ }^{b} \mathrm{CI}$ : competitive inhibition; ${ }^{\mathrm{c}} \mathrm{ND}$ : non described.

A common side effect of AChE inhibition treatments is anorexia [34,35], which strengthens the importance of natural AChE inhibitors as potential deterrents of predators such as fishes. Furthermore, the olfactory dysfunction in Alzheimer's disease has also been demonstrated [36]. Psammaplysene D is the major compound of the sponge $(0.66 \% w / w)$. It has been shown that tyrosine derived compounds are located in sphaerus cells of the sponge, allowing their release in the aquifer channels and further in the close environment of the sponge [37]. It would be thus interesting to track and quantify the concentration of this compound in the close reef environmental water of the sponges, using for example, solid phase adsorption toxin tracking (SPATT) [38], to allow the on field deterrent or reef protective activity of this compound acting softly on olfactory sense of predators in the marine environment. The importance of AChE inhibitors in the marine environment can be included in neuroecology of chemical defenses, a merging field of chemical ecology, which displays the importance of the links between ecology and evolution, secondary metabolites, behavior, and neurosciences [39].

\section{Material and Methods}

\subsection{General Procedures}

Optical rotations were measured using MCP-300 polarimeter (Anton Paar, Les Ulis, France). IR spectra were recorded on a BX FT-IR spectrometer (Perkin Elmer, Courtaboeuf, France). 1D and 2D NMR spectra were recorded on a Avance 500 and $600 \mathrm{MHz}$ (CNRS-ICSN, Bruker, Wissembourg, France). The chemical shifts are relative to the residual signal solvent $\left(\mathrm{CD}_{3} \mathrm{OD}: \delta_{\mathrm{H}} 3.31 ; \delta_{\mathrm{C}} 49.20\right.$; DMF- $\left.d_{7}: \delta_{\mathrm{H}} 8.03,2.92,2.75 ; \delta_{\mathrm{C}} 163.2,34.9,29.8\right)$. High-resolution mass spectra were obtained on a LCT Premier XE spectrometer (Waters, Guyancourt, France) in electrospray ionization mode by direct infusion of the purified compounds. Preparative HPLC was performed using Auto Prep system 
(Waters 600 controller and Waters 600 pump, equipped with a 996 Photodiode Array Detector, Waters, Guyancourt, France). A Varioskan ${ }^{\circledR}$ Flash microplate reader (Thermo Scientific, Villebon-sur-Yvette, France) was used for the acetylcholinesterase experiments.

\subsection{Animal Material}

The sponge was collected off the coast of Nuku Hiva $\left(8^{\circ} 55^{\prime} 977^{\prime}\right.$ S $\left.-140^{\circ} 01^{\prime} 17^{\prime} W\right)$ between 5 and $42 \mathrm{~m}$ deep using SCUBA on the 28 August 2009 [40]. It was identified as Suberea ianthelliformis and a reference specimen is deposited at the Queensland Museum (Brisbane, Australia) under the accessing number G331075.

\subsection{Isolation of Bioactive COMPOUNDS}

The freeze-dried sponge sample (960 g) of Suberea ianthelliformis was extracted three times at room temperature with a 1:1 mixture of $\mathrm{CH}_{2} \mathrm{Cl}_{2} / \mathrm{MeOH}(1.5 \mathrm{~L})$. The extracts were combined and dried under reduced pressure to afford a brown residue $(50 \mathrm{~g})$. Forty-five grams of this residue were partitioned between $\mathrm{CH}_{2} \mathrm{Cl}_{2}$ and $\mathrm{H}_{2} \mathrm{O}$. The resulting organic layer was collected and dried under reduced pressure to afford a brown material $(10.5 \mathrm{~g})$. The aqueous layer was further extracted with $n-\mathrm{BuOH}$ to afford the butanolic extract $(13 \mathrm{~g})$. The remaining aqueous fraction was dried to afford $21.2 \mathrm{~g}$ material. The $\mathrm{CH}_{2} \mathrm{Cl}_{2}$ extract was then subjected to normal phase silica-gel MPLC. A gradient composed of $\mathrm{CH}_{2} \mathrm{Cl}_{2} / \mathrm{MeOH}$ (1:0 to 0:1), followed by a mixture of EtOAc/Acetone/ $\mathrm{H}_{2} \mathrm{O} /$ Formic Acid $(5 / 3 / 0.5 / 0.5)$ were used to afford 8 fractions F1 to F8. The $n$-BuOH extract was also subjected to normal phase silica gel MPLC, using the same gradient as before to afford 6 fractions F1 to F6. Promising fractions were selected based on the LC-MS analytical profile, and then each fraction was submitted for purification by preparative reversed phase HPLC (column: Waters Sunfire $C_{18} 19 \mathrm{~mm} \times 150 \mathrm{~mm}$, $5 \mu, \mathrm{H}_{2} \mathrm{O}+0.1 \%$ formic acid $/ \mathrm{CH}_{3} \mathrm{CN}+0.1 \%$ formic acid). Some sub-fractions were further purified using semi-preparative reversed phase column (Waters Sunfire $\mathrm{C}_{18}, 10 \mathrm{~mm} \times 150 \mathrm{~mm}, 5 \mu, \mathrm{H}_{2} \mathrm{O}+0.1 \%$ formic acid $/ \mathrm{CH}_{3} \mathrm{CN}+0.1 \%$ formic acid).

Psammaplysene D (1): brown oil, (2.6 g); UV (MeOH) $\lambda_{\max }(\log \varepsilon) 241$ (1.30), 279 (2.90) nm; IR (neat) $v_{\max } 2943,1649,1598,1455,1379,738 \mathrm{~cm}^{-1} ;{ }^{1} \mathrm{H}$ and ${ }^{13} \mathrm{C}$ NMR data, Supporting Materials; HRESIMS $m / z 783.9673[\mathrm{M}+\mathrm{H}]^{+}$(calcd for $\mathrm{C}_{28} \mathrm{H}_{38} \mathrm{~N}_{3} \mathrm{O}_{3} \mathrm{Br}_{4}, 783.9606$ ).

Psammaplysene F (2): pale yellow oil, (18.4 mg); UV (MeOH) $\lambda_{\max }(\log \varepsilon) 208$ (0.84), 270 (0.20) nm; IR (neat) $v_{\max } 3381,2941,1636,1596,1471,1456,1399,1257,738 \mathrm{~cm}^{-1},{ }^{1} \mathrm{H}$ and ${ }^{13} \mathrm{C}$ NMR data, Table 1; HRESIMS $m / z 698.8675[\mathrm{M}+\mathrm{H}]^{+}$(calcd for $\mathrm{C}_{23} \mathrm{H}_{27} \mathrm{~N}_{2} \mathrm{O}_{3}{ }^{79} \mathrm{Br}_{2}{ }^{81} \mathrm{Br}_{2}, 698.8714$ ).

Psammaplysene G (3): white powder, (8.1 mg); UV (MeOH) $\lambda_{\max }(\log \varepsilon) 208$ (0.24), 270 (0.08) nm; IR (neat) $v_{\max } 2938,1600,1457,1398,1258,738 \mathrm{~cm}^{-1} ;{ }^{1} \mathrm{H}$ and ${ }^{13} \mathrm{C}$ NMR data, Table 1 ; HRESIMS $\mathrm{m} / z 698.8723$ $[\mathrm{M}+\mathrm{H}]^{+}$(calcd for $\mathrm{C}_{23} \mathrm{H}_{27} \mathrm{~N}_{2} \mathrm{O}_{3}{ }^{79} \mathrm{Br}_{2}{ }^{81} \mathrm{Br}_{2}, 698.8714$ ).

Psammaplysene $H$ (4)/Psammaplysene I (5) mixture: pale yellow oil, $(0.7 \mathrm{mg}) ;{ }^{1} \mathrm{H}$ and ${ }^{13} \mathrm{C}$ NMR data, Table 2; HRESIMS $m / z 769.9521[\mathrm{M}+\mathrm{H}]^{+}$(calcd. for $\mathrm{C}_{27} \mathrm{H}_{36}{ }^{79} \mathrm{Br}_{2}{ }^{81} \mathrm{Br}_{2} \mathrm{~N}_{3} \mathrm{O}_{3}, 769.9449$ )/HRESIMS $m / z 755.9309[\mathrm{M}+\mathrm{H}]^{+}$(calcd. for $\mathrm{C}_{26} \mathrm{H}_{34}{ }^{79} \mathrm{Br}_{2}{ }^{81} \mathrm{Br}_{2} \mathrm{~N}_{3} \mathrm{O}_{3}, 755.9293$ ).

Anomoian C (6): colorless oil, (1.9 mg); $[\alpha]_{\mathrm{D}}^{25}+9\left(c 0.19, \mathrm{MeOH}\right.$, as formate salt); UV (MeOH) $\lambda_{\max }(\log \varepsilon)$ 211 (0.80), $283(0.10) \mathrm{nm}$; IR (neat) $v_{\max } 3396,2938,1635,1458,1258,1039,737 \mathrm{~cm}^{-1} ;{ }^{1} \mathrm{H}$ and ${ }^{13} \mathrm{C}$ NMR data, Table 3; HRESIMS $m / z 743.9386[\mathrm{M}+\mathrm{H}]^{+}$(calcd for $\mathrm{C}_{25} \mathrm{H}_{34} \mathrm{~N}_{3} \mathrm{O}_{3}{ }^{79} \mathrm{Br}_{2}{ }^{81} \mathrm{Br}_{2}, 743.9293$ ).

Anomoian D (7): pale yellow oil, (1.2 mg); $[\alpha]_{\mathrm{D}}^{25}+11$ ( c 0.12, MeOH, as formate salt); UV (MeOH) $\lambda_{\max }$ (log ع) 227 (2.00), $283(0.40) \mathrm{nm}$; IR (neat) $v_{\max }$ 3356, 2934, 1600, 1598, 1458, 1259, 1041, $738 \mathrm{~cm}^{-1}$; ${ }^{1} \mathrm{H}$ and ${ }^{13} \mathrm{C}$ NMR data, Table 3; HRESIMS $m / z 729.9190[\mathrm{M}+\mathrm{H}]^{+}$(calcd for $\mathrm{C}_{24} \mathrm{H}_{32} \mathrm{~N}_{3} \mathrm{O}_{3}{ }^{79} \mathrm{Br}_{2}{ }^{81} \mathrm{Br}_{2}$, 729.9136). 
Anomoian E (8): colorless oil, $(3.8 \mathrm{mg}) ;[\alpha]_{\mathrm{D}}^{25}+7\left(\mathrm{c} 0.23, \mathrm{MeOH}\right.$, as formate salt); $\mathrm{UV}(\mathrm{MeOH}) \lambda_{\max }(\log \varepsilon)$ 222 (1.60), 276 (0.20) nm; IR (neat) $v_{\max } 3382,2937,2782,1635,1457,1257,1040,738 \mathrm{~cm}^{-1} ;{ }^{1} \mathrm{H}$ and ${ }^{13} \mathrm{C}$ NMR data, Table 4; HRESIMS $m / z$ 815.0068 [M + H] $]^{+}$(calcd for $\mathrm{C}_{29} \mathrm{H}_{43} \mathrm{~N}_{4} \mathrm{O}_{3}{ }^{79} \mathrm{Br}_{2}{ }^{81} \mathrm{Br}_{2}, 815.0028$ ).

Anomoian F (9): yellow oil, $(3.8 \mathrm{mg}) ;[\alpha]_{\mathrm{D}}^{25}+6\left(c\right.$ 0.38, MeOH, as formate salt); $\mathrm{UV}(\mathrm{MeOH}) \lambda_{\max }(\log \varepsilon)$ 220 (1.30), $277(0.20) \mathrm{nm}$; IR (neat) $v_{\max } 3402,2940,2780,1641,1460,1258,1041,737 \mathrm{~cm}^{-1} ;{ }^{1} \mathrm{H}$ and ${ }^{13} \mathrm{C}$ NMR data, Table 4; HRESIMS $m / z$ 829.0259 [M + H] $]^{+}$(calcd for $\mathrm{C}_{30} \mathrm{H}_{45} \mathrm{~N}_{4} \mathrm{O}_{3}{ }^{79} \mathrm{Br}_{2}{ }^{81} \mathrm{Br}_{2}, 829.0184$ ).

$N$, N-Dimethyldibromotyramine (10): yellow oil, (10.5 mg); UV (MeOH) $\lambda_{\max }(\log \varepsilon) 222$ (1.50), 291 (0.60) nm; IR (neat) $v_{\max } 3255,2957,1636,1596,1283,737 \mathrm{~cm}^{-1} ;{ }^{1} \mathrm{H}$ and ${ }^{13} \mathrm{C}$ NMR data, Supplementary Materials; HRESIMS $m / z 323.9388[\mathrm{M}+\mathrm{H}]^{+}$(calcd for $\mathrm{C}_{10} \mathrm{H}_{14} \mathrm{NO}^{79} \mathrm{Br}^{81} \mathrm{Br}, 323.9422$ ).

5-Hydroxy xanthenuric acid (11): reddish brown amorphous material, (3.2 mg); UV (MeOH) $\lambda_{\max }(\log \varepsilon)$ 210 (0.55), 236 (0.8), $336(0.20) \mathrm{nm}$; IR (neat) $v_{\max } 3360,3250,2980,1726,1644,1590,1447,1246,1051$, $757,683 \mathrm{~cm}^{-1} ;{ }^{1} \mathrm{H}$ and ${ }^{13} \mathrm{C}$ NMR data, Supplementary Materials; HRESIMS $\mathrm{m} / z 222.0441[\mathrm{M}+\mathrm{H}]^{+}$ (calcd for $\mathrm{C}_{10} \mathrm{H}_{8} \mathrm{NO}_{5}, 222.0402$ ).

Xanthurenic acid (12): pale green oil, (1.5 mg); UV (MeOH) $\lambda_{\max }(\log \varepsilon) 220$ (0.35), 248 (0.60), 345 (0.15) $\mathrm{nm} ;{ }^{1} \mathrm{H}$ and ${ }^{13} \mathrm{C}$ NMR data, Supplementary Materials; HRESIMS $m / z 206.0511[\mathrm{M}+\mathrm{H}]^{+}$(calcd for $\mathrm{C}_{10} \mathrm{H}_{8} \mathrm{NO}_{4}$, 206.0453).

\subsection{Cell Culture and Cell Proliferation Assay}

The human cell line KB originated from the National Cancer Institute (NCI) and was grown in Dulbecco's Modified Eagle Medium (D-MEM) medium supplemented with 10\% foetal calf serum, in the presence of penicillin, streptomycin, and fungizone in a $75 \mathrm{~mL}$ flask under $5 \% \mathrm{CO}_{2}$. A total of 600 cells were plated in 96-well tissue culture plates in $200 \mathrm{~L}$ of medium and treated $24 \mathrm{~h}$ later with $2 \mu \mathrm{L}$ of stock solution of compounds dissolved in DMSO using a Biomek 3000 (Beckman-Coulter, Brea, CA, USA). Controls received the same volume of DMSO (1\% final volume). After $72 \mathrm{~h}$ exposure, cell titer 96 Aqueous One solution (Promega, Madison, WI, USA) was added and incubated for $3 \mathrm{~h}$ at $37{ }^{\circ} \mathrm{C}$ : the absorbance was monitored at $490 \mathrm{~nm}$, and results were expressed as the inhibition of cell proliferation calculated as the ratio [(1 - (OD490 treated/OD490 control $)) \times 100]$ in triplicate experiments.

\subsection{Acetylcholinesterase Inhibition Assay}

The crude extract of the sponge and the purified psammaplysene $\mathrm{D}(\mathbf{1})$ were dissolved in DMSO at $10 \mathrm{mg} / \mathrm{mL}$, stored at $-20^{\circ} \mathrm{C}$ and diluted subsequently 100 times in $\mathrm{H}_{2} \mathrm{O}$ prior testing. Determination of AChE-inhibitory activity was measured according the Ellman's colorimetric method [41], in 96-well tissue culture plates. All reagents, buffers and salts were purchased from Sigma-Aldrich (Saint-Louis, MO, USA). Galantamine was used as a positive control for each analysis. Solvent controls received the same volume of water. After a $30 \mathrm{~min}$ incubation at $25^{\circ} \mathrm{C}$ in the dark, absorbance was monitored at $\lambda=405 \mathrm{~nm}$. Results were expressed as the percentage of enzyme inhibition calculated as the ratio: $100 \times\left(\mathrm{OD}_{\text {control }}-\mathrm{OD}_{\text {treated }}\right) /\left(\mathrm{OD}_{\text {control }}-\mathrm{OD}_{\text {blank }}\right)$, where the blanks are the wells without AChE. Serial dilutions of the compound or extract were prepared (100, 50, 25, 12.5, 6.25, 3.12, 1.56 , and $0.78 \mu \mathrm{g} / \mathrm{mL}$ ) and tested according to the same procedure using $10 \mu \mathrm{L}$ of each solution. $\mathrm{IC}_{50}$ values were graphically determined by plotting the percentage of inhibition against the compound concentrations. Each assay was performed in triplicate and results are expressed as mean values \pm S.D.

\subsubsection{Kinetic Study}

The inhibition mode of psammaplysene $\mathrm{D}$ on $\mathrm{AChE}$ was determined while measuring the enzyme activity in presence of an increasing concentration of ATCI $(0.024,0.049,0.098,0.19,0.39,0.78,1.57$, and $3.15 \mu \mathrm{M}$ ), in absence or presence of $2 \mu \mathrm{g} / \mathrm{mL}$ final concentration of purified psammaplysene $\mathrm{D}$. 
The inhibition mode, $V_{\max }$, and $\mathrm{K}_{\mathrm{M}}$ values were determined by double-reciprocal Lineweaver and Burk plot analysis (1934) of the data obtained.

\subsubsection{Guppy Bioassay}

5 to $8 \mathrm{~cm}$ long guppies (Poecilia reticulata) were collected at night in a private fresh water pool at Papara (Tahiti, French Polynesia) and immediately acclimated at the laboratory temperature $\left(25^{\circ} \mathrm{C}\right)$. After acclimatization, fishes were parted in two $2 \mathrm{~L}$ tanks: one for the control group treated with solvent $(N=5)$. Another experiment was performed using a $1 \mathrm{~h}$ treatment with $100 \mu \mathrm{g} / \mathrm{mL}$ of crude extract of the sponge or purified psammaplysene $\mathrm{D}(\mathbf{1})$ to check their acute toxicity.

\subsubsection{Reef Fish Feeding Behavior Experiment}

Manini (Acanthurus triostegus) were caught during new moon nights on the foreshore puddles at Tema'e public beach [42]. Recruits (fish larvae undergoing metamorphosis) and juveniles (larvae after the recruits stage) were collected and immediately used for the experiments. Natural lagoon sea-water was used and UV-sterilized prior use. Three conditions were tested on three groups: control, solvent, $1 \mu \mathrm{g} / \mathrm{mL}$ sponge extract treatment, with 4 or 5 fishes in each $3 \mathrm{~L}$ tank. The fishes were exposed under semi-static system for $72 \mathrm{~h}$, the experimental solutions were renewed every $24 \mathrm{~h}$ to maintain clean experimental conditions. The experiments were performed with fish recruits and juveniles. Rubbles were disposed in each aquarium $1 \mathrm{~h}$ /day during 3 days. Feeding behavior experiment consists in counting the overall number of bites on those rubbles in each aquarium. Six videos sequences $(N=6)$ of 5 or 10 min per aquarium and per day were analyzed. Results are expressed in number of bites per fish and per hour.

\subsubsection{Statistical Analysis}

All the values of AChE activity are represented in a boxplot distribution, because of non-normality of variable distribution $(N=4$ or 5$)$. The significant differences between controls and treatments ( $p$-value $p<0.05$ ) were analyzed with non-parametric test of Wilcoxon Mann Whitney. In feeding deterrent assay, pairs significant differences between different conditions $(p<0.05)$ were tested with non-parametric Kruskal Wallis test. All statistical assays were executed using R software (R-3.2.0, The R Foundation for Statistical Computing, Vienna, Austria).

\section{Conclusions}

This paper describes the isolation of eight new bromotyrosine secondary metabolites from the Polynesian Sponge Suberea ianthelliformis. Their structures are close to those of psammaplysenes and anomoians but all displaying methylated amidic nitrogen and rotameric mixtures. Since flexible syntheses were developed for psammaplysene A [43], and iso-anomoian A [28] and other analogues, our molecules present new derivatives for further optimization of biologically interesting molecules. They all exhibited moderate antiproliferative activity against KB cancer cell lines, but psammaplysene $\mathrm{D}$ (1) displayed substantial cytotoxicity as well as acetylcholinesterase inhibition with $\mathrm{IC}_{50}$ values of $0.7 \mu \mathrm{M}$ and $1.3 \mu \mathrm{M}$, respectively. It would be interesting to further investigate the ecological role of the major psammaplysene D as chemical anti-predatory defenses through fish antifeedant activity. The available synthetic strategies would allow the preparation of our metabolites and a rage of their analogues for the screening of the inhibition of various cancer cell lines and SAR studies.

Supplementary Materials: The following are available online at http:/ /www.mdpi.com/1660-3397/16/5/146/s1, Spectroscopic Data (HRMS, ${ }^{1} \mathrm{H}$ NMR, ${ }^{13} \mathrm{C}$ NMR, COSY, HSQC and HMBC) for compounds 1-12.

Author Contributions: Ali Al-Mourabit and Cécile Debitus designed the project and the whole experiment and prepared the manuscript. Amr El-Demerdash and Céline Moriou did the chemical experimental part (isolation and structural identification of the compounds) and wrote the first draft of manuscript. The biological assays were designed and performed by Jordan Toullec, Marc Besson and David Lecchini on fish, by Stéphanie Soulet on acetylcholinesterase, by Nelly Schmitt on KB cells. Cécile Debitus and Sylvain Petek organized the field 
work and sponge collection, the conditioning and the realization of the library of extracts in preliminary to this thorough study.

Acknowledgments: We thank the French Polynesian authorities, as well as the communities, for allowing us to collect in Marquesas Islands. Financial support from CNRS-ICSN, IRD for the collecting trip aboard R/V Alis, French and French Polynesian governments for the Marquesas and Biopolyval projects, ANR (POMARE project, 2011-EBIM-006-01), as well as project TASCMAR which is funded by the European Union under grant agreement number 634674. Labex MER and Labex CORAIL, are gratefully acknowledged. Amr El-Demerdash's PhD was granted and financed by the Egyptian Government (Egyptian Cultural Bureau in Paris, Ministry of Higher Education), they are gratefully acknowledged. We thank IRD's diving team (SEOH IRD Noumea, New Caledonia) and the R/V crew for their on-field help, O. Thoison for HPLC assistance J.-F. Gallard and K. Hammad for technical assistance and NMR measurements, J. Bignon for cytotoxicity evaluations. We gratefully acknowledge Laurent Calcul for the improvements to this manuscript.

Conflicts of Interest: The authors declare no conflict of interest.

\section{References}

1. Rahboek, L.; Christophersen, C. The Alkaloids: Chemistry and Biology; Academic Press: Cambridge, MA, USA, 2001; Volume 57, p. 185.

2. Nuñez, C.V.; Almeida, E.V.R.; Granato, A.C.; Marques, S.O.; Santos, K.O.; Pereira, F.R.; Macedo, M.L.; Ferreira, A.G.; Hajdu, E.; Pinheiro, U.S.; et al. Chemical variability within the marine sponge Aplysina fulva. Biochem. Syst. Ecol. 2008, 36, 283-296. [CrossRef]

3. Puyana, M.; Pawlik, J.; Blum, J.; Fenical, W. Metabolite variability in Caribbean sponges of the genus Aplysina. Rev. Bras. Farmacogn. 2015, 25, 592-599. [CrossRef]

4. König, G.M.; Wright, A.D. Agelorins A and B, and 11-Epi-fistularin-3, Three New Antibacterial Fistularin-3 Derivatives from the Tropical Marine Sponge Agelas oroides. Heterocycles 1993, 36, 1351-1358. [CrossRef]

5. Nicacio, K.J.; Ióca, L.P.; Fróes, A.M.; Leomil, L.; Appolinario, L.R.; Thompson, C.C.; Thompson, F.L.; Ferreira, A.G.; Williams, D.E.; Andersen, R.J.; et al. Cultures of the Marine Bacterium Pseudovibrio denitrificans Ab134 Produce Bromotyrosine-Derived Alkaloids Previously Only Isolated from Marine Sponges. J. Nat. Prod. 2017, 80, 235-240. [CrossRef] [PubMed]

6. Erpenbeck, D.; Van Soest, R.W.M. Status and Perspective of Sponge Chemosystematics. Mar. Biotechnol. 2007, 9, 2-19. [CrossRef] [PubMed]

7. Shaker, K.H.; Zinecker, H.; Ghani, M.A.; Imhoff, J.F.; Schneider, B. Bioactive metabolites from the sponge Suberea sp. Chem. Biodivers. 2010, 7, 2880-2887. [CrossRef] [PubMed]

8. Hirano, K.; Kubota, T.; Tsuda, M.; Watanabe, K.; Fromont, J.; Kobayashi, J. Ma'edamines A and B, cytotoxic bromotyrosine alkaloids with a unique $2(1 \mathrm{H})$ pyrazinone ring from Sponge Suberea sp. Tetrahedron 2002, 56, 8107-8110. [CrossRef]

9. Tsuda, M.; Sakuma, Y.; Kobayashi, J. Suberedamines A and B, new bromotyrosine alkaloids from a sponge Suberea species. J. Nat. Prod. 2001, 64, 950-982. [CrossRef]

10. Kijjoa, A.; Watanadilok, R.; Sonchaeng, P.; Puchakarn, S.; Sawangwong, P.; Herz, W. Bromotyrosine derivatives from the marine sponge Suberea aff. praetensa. Boll. Mus. Ist. Biol. Univ. Genova 2004, 68, 391-397.

11. Florean, C.; Schnekenburger, M.; Lee, J.; Kim, K.R.; Mazumder, A.; Song, S.; Kim, J.; Grandjenette, C.; Kim, J.; Yoon, A.; et al. Discovery and characterization of Isofistularin-3, a marine brominated alkaloid, as a new DNA demethylating agent inducing cell cycle arrest and sensitization to TRAIL in cancer cells. Oncotarget 2016, 7, 24027-24049. [CrossRef] [PubMed]

12. Shaala, L.A.; Youssef, D.T.A.; Badr, J.M.; Sulaiman, M.; Kherd, A. Bioactive secondary metabolites from the Red Sea marine Verongid sponge Suberea species. Mar. Drugs 2015, 13, 1621-1631. [CrossRef] [PubMed]

13. Shaala, L.A.; Khalifa, S.I.; Mesbah, M.K.; van Soest, R.W.M.; Youssef, D.T.A. Subereaphenol A, a new cytotoxic and antimicrobial dibrominated phenol from the Red Sea sponge Suberea mollis. Nat. Prod. Commun. 2008, 3, 219-222. [CrossRef]

14. Abou-Ashour, M.I.; Shaala, L.A.; Youssef, D.T.A.; Bader, J.M.; Habib, A.M. Bioactive brominated metabolites from the Red Sea sponge Suberea mollis. J. Nat. Prod. 2008, 71, 1464-1467. [CrossRef] [PubMed]

15. Shaala, L.A.; Bamane, F.H.; Badr, J.M.; Youssef, D.T.A. Brominated arginine-derived alkaloids from the Red Sea sponge Suberea mollis. J. Nat. Prod. 2001, 74, 1517-1520. [CrossRef] [PubMed] 
16. Xu, M.; Davis, R.A.; Feng, Y.; Sykes, M.L.; Shelper, T.; Avery, V.M.; Camp, D.; Quinn, R.J. Ianthelliformisamines A-C, antibacterial bromotyrosine-derived metabolites from the marine sponge Suberea ianthelliformis. J. Nat. Prod. 2012, 75, 1001-1005. [CrossRef] [PubMed]

17. Mani, L.; Jullian, V.; Mourkazel, B.; Valentin, A.; Dubois, J.; Cresteil, T.; Folcher, E.; Hooper, J.N.A.; Erpenbeck, D.; Aalbersberg, W.; et al. New antiplasmodial bromotyrosine derivatives from Suberea ianthelliformis (Lendenfeld, 1888). Chem. Biodivers. 2012, 9, 1436-1451. [CrossRef] [PubMed]

18. El-Demerdash, A.; Moriou, C.; Martin, M.T.; Rodrigues-Stien, A.; Petek, S.; Demoy-Schnider, M.; Hall, K.; Hooper, J.N.A.; Debitus, C.; Al-Mourabit, A. Cytotoxic guanidine alkaloids from a French Polynesian Monanchora n. sp. sponge. J. Nat. Prod. 2016, 79, 1929-1937. [CrossRef] [PubMed]

19. Kashman, Y.; Groweiss, A.; Shmueli, U. Latrunculin, A new 2-thiazolidinone macrolide from the marine Sponge Latrunculia magnifica. Tetrahedron Lett. 1980, 21, 3629-3632. [CrossRef]

20. Neeman, I.; Fishelson, L.; Kashman, Y. Isolation of a new toxin from the sponge Latrunculia magnifica in the Gulf of Aquaba (Red Sea). Mar. Biol. 1975, 30, 293-296. [CrossRef]

21. Buchanan, M.S.; Carroll, A.R.; Addepalli, R.; Avery, V.M.; Hooper, J.N.A.; Quinn, R.J. Psammaplysenes C and D, Cytotoxic Alkaloids from Psammoclemma sp. J. Nat. Prod. 2007, 70, 1827-1829. [CrossRef] [PubMed]

22. Yin, L.W.; Feng, Y.; Shimizu, Y.; Pfeifer, T.; Wellington, C.; Hooper, J.N.A.; Quinn, R. Aplysinellamides A-C, Bromotyrosine-Derived Metabolites from an Australian Aplysinella sp. Marine Sponge. J. Nat. Prod. 2014, 77, 1210-1214. [CrossRef]

23. Molinski, T.F.; Faulkner, D.J. An antibacterial pigment from the sponge Dendrilla membranosa. Tetrahedron Lett. 1988, 29, 2137-2138. [CrossRef]

24. Spectral Data for Xanthurenic Acid Are Available on Line at the Spectral Database for Organic Compounds. Available online: http://sdbs.db.aist.go.jp/sdbs/cgi-bin/cre_index.cgi (accessed on 26 April 2018).

25. Schroeder, F.C.; Kau, T.R.; Silver, P.A.; Clardy, J. The Psammaplysenes, Specific Inhibitors of FOXO1a Nuclear Export. J. Nat. Prod. 2005, 68, 574-576. [CrossRef] [PubMed]

26. Kernan, M.R.; Cambie, R.C.; Bergquist, P.R. Chemistry of Sponges, VIII. Anomoian A, a Bromotyrosine Derivative from Anomoiantbella popeae. J. Nat. Prod. 1990, 53, 720-723. [CrossRef]

27. Tarazone, G.; Santamaria, G.; Cruz, P.G.; Ferandez, R.; Pérez, M.; Martinez-Leal, J.F.; Rodriguez, J.; Jiménez, C.; Cuevas, C. Cytotoxic Anomoian B and Aplyzanzine B, New Bromotyrosine Alkaloids from Indonesian Sponges. ACS Omega 2017, 2, 3494-3501. [CrossRef]

28. Kottakota, S.K.; Evangelopoulos, D.; Alnimr, A.; Bhakta, S.; McHugh, T.D.; Gray, G.; Groundwater, P.W.; Marrs, E.C.L.; Perry, J.D.; Spilling, C.D.; et al. Synthesis and Biological Evaluation of Purpurealidin E-Derived Marine Sponge Metabolites: Aplysamine-2, Aplyzanzine A, and Suberedamines A and B. J. Nat. Prod. 2012, 75, 1090-1101. [CrossRef] [PubMed]

29. Bocquené, G.; Galgani, F. Biological Effects of Contaminants: Cholinesterase Inhibition by Organophosphate and Carbamate Compounds; ICES Techniques in Marine Environmental Sciences, No. 22; International Council for the Exploration of the Sea: Copenhagen, Denmark, 1998.

30. Silva, T.; Reis, J.; Teixeira, J.; Borges, F. Alzheimer's disease, enzyme targets and drug discovery struggles: From natural products to drug prototypes. Ageing Res. Rev. 2014, 15, 116-145. [CrossRef] [PubMed]

31. Olatunji, O.J.; Ogundajo, A.L.; Oladosu, I.A.; Changwichit, K.; Ingkanina, K.; Yuenyongsawad, S.; Plubrukarn, A. Non-competitive inhibition of acetylcholinesterase by bromotyrosine alkaloids. Nat. Prod. Commun. 2014, 9, 1559-1561. [PubMed]

32. Sirimangkalakitti, N.; Olatunji, O.J.; Changwichit, K.; Saesong, T.; Chamni, S.; Chanvorachote, P.; Ingkaninan, K.; Plubrukarn, A.; Suwanborirux, K. Bromotyrosine Alkaloids with Acetylcholinesterase activity from the Thai sponge Aconthodendrilla sp. Nat. Prod. Commun. 2015, 10, 1945-1949. [PubMed]

33. Sepcic, K.; Mancini, I.; Vidic, I.; Jovan, U.; Frassanito, R.; Pietra, F.; Macek, P.; Turk, T. Antibacterial and anticholinesterase activities of aplysamine-4, a bromotyrosine-derived metabolite of a Red Sea marine sponge. J. Nat. Toxins 2001, 10, 181-191. [PubMed]

34. Schneider, S.L. A critical review of cholinesterase inhibitors as a treatment modality in Alzheimer's disease. Dialogues Clin. Neurosci. 2000, 2, 111-128.

35. Aagaard, L. Chapter 1-Central nervous system stimulants and drugs that suppress appetite. Side Effects Drugs Annu. 2014, 35, 1-25.

36. Zou, Y.; Lu, D.; Liu, L.; Zhang, H.; Zhou, Y. Olfactory dysfunction in Alzheimer's disease. Neuropsychiatr. Dis. Treat. 2016, 12, 869-875. [CrossRef] [PubMed] 
37. Thompson, J.E.; Barrow, K.D.; Faulkner, D.J. Localization of Two Brominated Metabolites, Aerothionin and Homoaerothinin, in Spherulous cells of the Marine Sponge Aplysina fistularis (=Verongia thiona). Acta Zool. 1983, 64, 199-210. [CrossRef]

38. Lane, J.Q.; Roddam, C.M.; Langlois, G.W.; Kudela, R.M. Application of Solid Phase Adsorption Toxin Tracking (SPATT) for field detection of the hydrophilic phycotoxins domoic acid and saxitoxin in coastal California. Limnol. Oceanogr. Methods 2010, 8, 645-660. [CrossRef]

39. Derby, C.D.; Aggio, J.F. The Neuroecology of Chemical Defenses. Integr. Comp. Biol. 2011, 51, 771-780. [CrossRef] [PubMed]

40. Debitus, C. BSMPF-1 Cruise, RV Alis, 2009. Available online: http://dx.doi.org/10.17600/9100030 (accessed on 26 April 2018).

41. Ellman, G.L.; Courtney, D.; Andres, V.; Featherstone, R.M. A new and rapid colorimetric determination of acetylcholinesterase activity. Biochem. Pharmacol. 1961, 7, 88-95. [CrossRef]

42. Lecchini, D.; Dufour, V.; Carleton, J.; Strand, S.; Galzin, R. Estimating the Patch size of larval fishes during colonization on coral reefs. J. Fish Biol. 2004, 65, 1142-1146. [CrossRef]

43. Georgiades, S.N.; Clardy, J. Total Synthesis of Psammaplysenes A and B, Naturally Occurring Inhibitors of FOXO1a Nuclear Export. Org. Lett. 2005, 7, 4091-4094. [CrossRef] [PubMed]

(C) 2018 by the authors. Licensee MDPI, Basel, Switzerland. This article is an open access article distributed under the terms and conditions of the Creative Commons Attribution (CC BY) license (http://creativecommons.org/licenses/by/4.0/). 